\title{
Representation through Legislative Redistricting: A Stochastic Model*
}

\author{
Gary King, Harvard University
}

This paper builds a stochastic model of the processes that give rise to observed patterns of representation and bias in congressional and state legislative elections. The analysis demonstrates that partisan swing and incumbency voting, concepts from the congressional elections literature, have determinate effects on representation and bias, concepts from the redistricting literature. The model shows precisely how incumbency and increased variability of partisan swing reduce the responsiveness of the electoral system and how partisan swing affects whether the system is biased toward one party or the other. Incumbency, and other causes of unresponsive representation, also reduce the effect of partisan swing on current levels of partisan bias.

By relaxing the restrictive portions of the widely applied "uniform partisan swing" assumption, the theoretical analysis leads directly to an empirical model enabling one more reliably to estimate responsiveness and bias from a single year of electoral data. Applying this to data from seven elections in each of six states, the paper demonstrates that redistricting has effects in predicted directions in the short run: partisan gerrymandering biases the system in favor of the party in control and, by freeing up seats held by opposition party incumbents, increases the system's responsiveness. Bipartisan-controlled redistricting appears to reduce bias somewhat and dramatically to reduce responsiveness. Nonpartisan redistricting processes substantially increase responsiveness but do not have as clear an effect on bias. However, after only two elections, prima facie evidence for redistricting effects evaporate in most states. Finally, across every state and type of redistricting process, responsiveness declined significantly over the course of the decade. This is clear evidence that the phenomenon of "vanishing marginals," recognized first in the U.S. Congress literature, also applies to these different types of state legislative assemblies. It also strongly suggest that redistricting could not account for this pattern.

\section{Introduction}

Representative democracies generally group citizens into legislative constituencies. Individuals living throughout each state are geographically segmented into legislative districts; this, in turn, creates a particular set of voter preferences within each district and hence a specific statewide allocation of legislative seats to each political party. In the United States, congressional and state legislative district lines are redrawn approximately every decade. This creates new opportunities for partisan gerrymanderers to seek to gain political advantage, incumbents to insulate themselves from electoral swings, and the courts to impose a system of "fair" representation.

* Thanks to Chris Achen, Jim Alt, Neal Beck, Bruce Cain, Andrew Gelman, and Elizabeth Rosenthal for many helpful discussions and comments. Robert Browning also made significant contributions at an early stage in this research. Thanks also to the National Science Foundation for research support grants SES-87-22715 and SES-89-09201.

American Journal of Political Science, Vol. 33, No. 4, November 1989, Pp. 787-824

(C) 1989 by the University of Texas Press, P.O. Box 7819, Austin, TX 78713 
Although the allocation of an individual legislative seat to a political party within each district depends deterministically and unambiguously on citizen votes through the winner-take-all rule, the basic character of the state's electoral system is defined only at the statewide level by aggregating these individual districts. For example, gerrymandering is never a problem when considering only a single district, since the winner-take-all rule still treats both parties fairly; however, the aggregation of these districts, in combination with the geographic distribution of partisans and the configuration of district lines, produces a "stochastic" (probabilistic) relationship between the statewide division of votes a party receives and the aggregate allocation of seats among the parties.

The redistricting process also influences the form of democratic representation and the degree and direction of partisan bias-concepts that are inherently defined only on the level of the political system. Many scholars have analyzed the effects of redistricting (e.g., Grofman and Lijphart 1986; Cain 1984; Grofman et al. 1982; Polsby 1971), but few have incorporated in their models the dynamic features of elections, such as incumbency and partisan swing. ${ }^{1}$

In this paper I first extend the aggregate theory of representation in King and Browning (1987) to include cases where the allocation of legislative seats is relatively unresponsive to citizen votes. This extension unifies the literature on redistricting with recent empirical findings that U.S. congressional elections are becoming less competitive (e.g., Mayhew 1971, 1974; Ferejohn 1977; Fiorina 1977; Ansolabehere, Brady, and Fiorina 1988). In the core of this paper, I then develop a district-level theoretical model of the process by which partisan electoral swings and incumbency voting modify democratic representation and partisan bias. Using this model and an empirical estimation of it, I analyze the more basic phenomena that give rise to the extant aggregate patterns of representation and bias, first described by Tufte (1973). In total, this analysis formally links the concepts of representation and partisan bias from the seats-votes literature with factors such as incumbency and partisan swing from the congressional elections literature-two substantively related fields with too few cross-citations and even fewer unified models. It generalizes and relaxes the widely used, but quite restrictive and often unrealistic, "uniform partisan swing" assumption introduced almost four decades ago by Butler (1951). The paper modifies the essentially "static" seats-votes models in the literature to include dynamic change and to provide reliable estimates of bias and representation with data from only a

'Previous court decisions have constrained the redistricting process only slightly by requiring that every district contain equal numbers of citizens, that districts be contiguous, and that the redistricting not dilute minority voting strength. However, beyond these judicial requirements and the winner-take-all rule within each single-member district, the state imposes no constitutional or statutory rule constraining the relationship between the statewide proportion of votes a party receives and its allocation of legislative seats. 
single election. It also demonstrates the value of stochastic modeling for political science research. ${ }^{2}$

\section{Conceptualizing Representation and Bias: The Seats-Votes Curve}

This section reviews and extends the basic concepts of representation and bias, defined at the statewide level in an idealized two-party electoral system. I use the names "Democratic" and "Republican" for these two parties and refer explicitly to state legislative elections, but the model presented here applies in principle to any two-party system with single-member electoral districts. In the section after this, I derive a district-level model that demonstrates what gives rise to these statewide relationships.

Following King and Browning (1987), I define an unbiased electoral system as partisan symmetry in the seats-votes relationship: in a two-party system, the absence of bias is the situation where each political party is allocated the same proportion of seats for an equivalent proportion of votes. ${ }^{3} \mathrm{~A}$ two-party electoral system with partisan bias is asymmetric in that it enables one of the political parties to receive more seats for a given proportion of votes than the opposition party would receive. ${ }^{4}$

Note that partisan symmetry does not necessarily imply de facto proportional representation, where the proportion of statewide Democratic votes translates into the same proportion of statewide Democratic seats. Indeed, many forms of fair representation can exist. For example, the first column of Figure 1 gives six examples of fair electoral systems (please ignore the second column of the figure for the moment). Each of these examples has the proportion of statewide Democratic votes across the horizontal axis (marked as $E(V)$ ) and the proportion Democratic seats on the vertical axis (marked as $E(S)$ ). Each graph in this column of Figure 1 represents an electoral system that is symmetric with respect to the parties. ${ }^{5}$ For example, in the fourth graph (labeled $\rho=3$ ), consider an election where the Democrats received $60 \%$ of the vote. To determine the allocation of legislative seats, move from $E(V)=0.6$ vertically to the curve and then horizontally to the $Y$ axis; in this case, if the Democrats received $60 \%$

${ }^{2}$ Although I address other types of distortion, the only type of bias the model here includes is partisan. The most significant omission caused by this focus is the exclusion of racial gerrymandering as a possible longer lasting effect on the electoral system.

${ }^{3}$ See Grofman (1983) for alternative definitions of partisan bias.

${ }^{4}$ In any one election, each party actually receives only a single fixed proportion of votes and seats, but in theory this particular election is an outcome from the set of all possible outcomes generated by the same underlying electoral system. This underlying electoral system, more than any one particular election, is the focus of this study.

${ }^{5}$ An easy way to check for symmetry is to change the axes from proportion Democratic seats and votes to proportion Republican seats and votes. If the interpretation remains unchanged, the system is symmetric with respect to the parties and hence unbiased. 
FIGURE 1

Forms of Fair Representation $(\lambda=0)$

Seats-Votes Curves
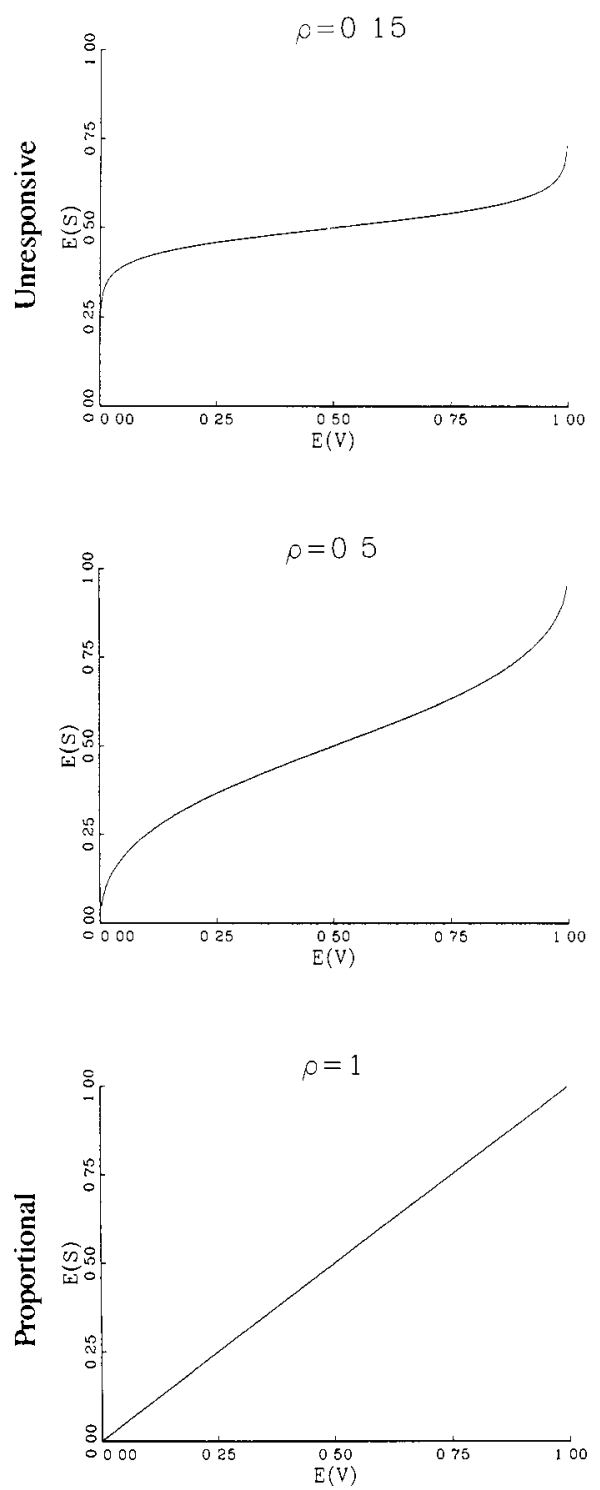

Mean Voter Preference Distributions
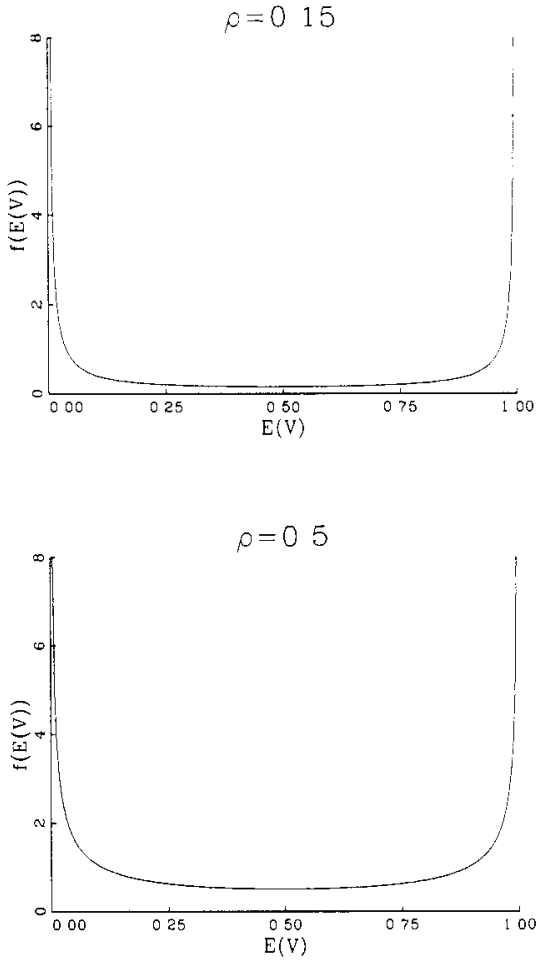

$p=1$

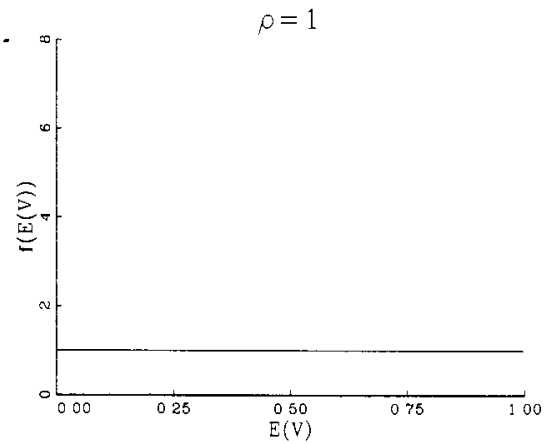


FIGURE 1 (cont.)

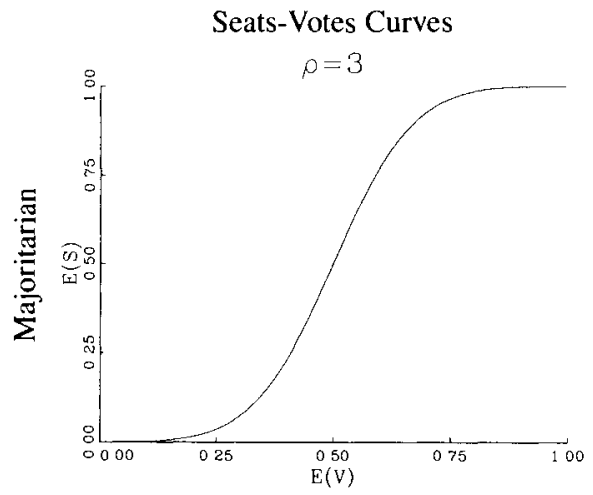

Mean Voter Preference Distributions
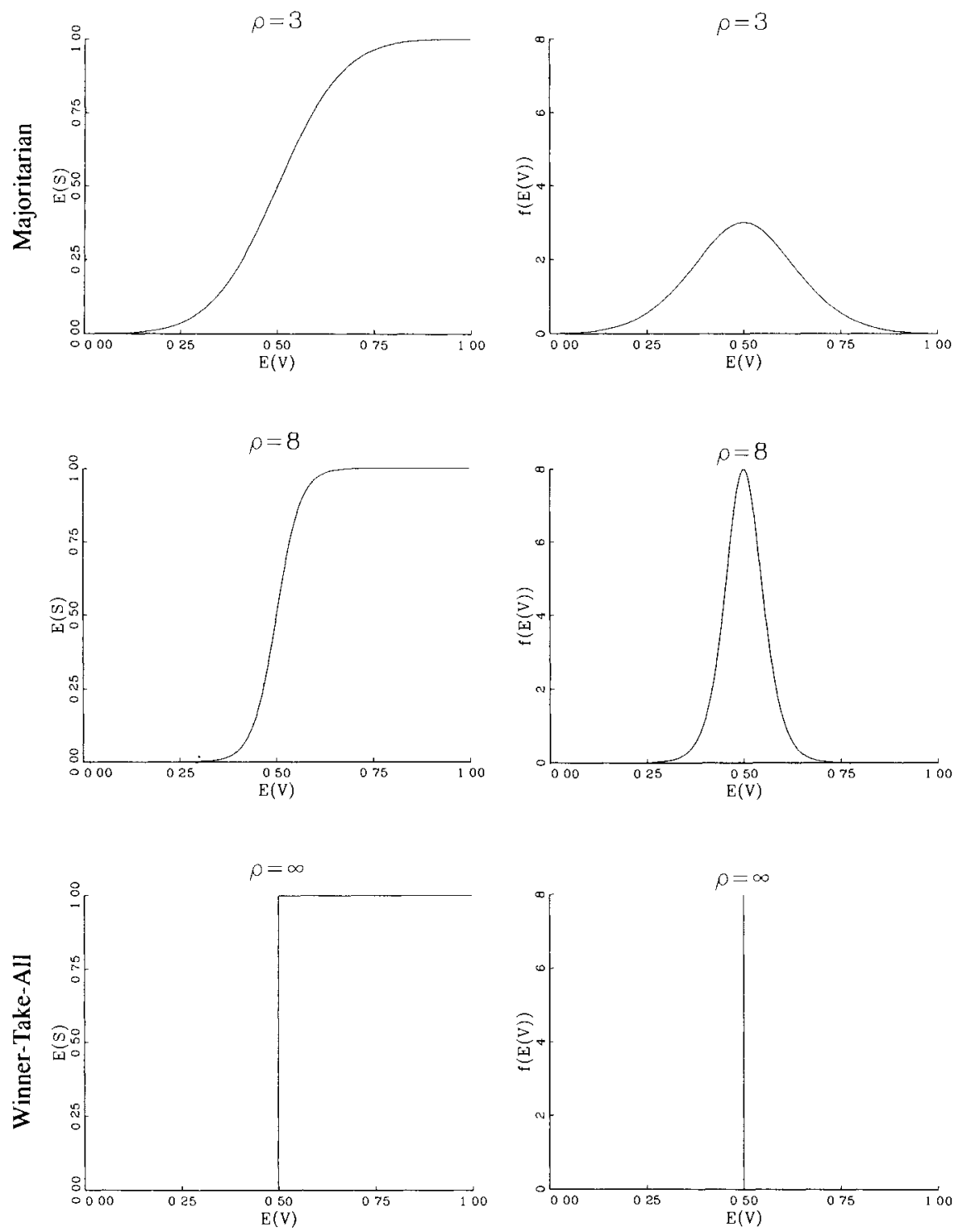
of the vote, they are allocated $77 \%$ of the legislative seats on average. This is not proportional, but it is still fair, since if the Republicans were to receive $60 \%$ of the vote $(1-E(V)=0.6)$, they too would be allocated $77 \%(1-E(S)=$ $0.77)$ of the seats.

In addition to being symmetric, all six figures pass through three points: 0 , $0 ; 0.5,0.5$, and 1,1 . The curves must pass through the endpoints, since if one party receives every vote statewide, only election fraud would keep it from taking all the seats. In addition, all fair curves must pass through the midpoint, since this is the point around which they are symmetric.

However, even with these constraints, one can imagine a large number of different, fair seats-votes curves. The six in the first column of Figure 1 are arranged according to the form of democratic representation, indexed by the parameter $\rho$. At one extreme of fair representation are electoral systems that are unresponsive $(0<\rho<1)$, with the proportion of seats for a party reacting only sluggishly to even large changes in votes for that party. This pattern can be seen in the two seats-votes curves that are relatively flat over most of their range in the first column of Figure 1 ( $\rho=0.15$ and $\rho=0.50$ ). Across all the figures, as $\rho$ gets larger, the center of the seats-votes curves become steeper; that is, the proportion of seats allocated between the parties is more sensitive to changes in voter preferences in this range. A logical midpoint is proportional representation $(\rho=1)$, where $S=V$ and the legislature reflects the distribution of voter preferences as faithfully as possible.

Some degree of reflection in representation is clearly important in two-party democratic electoral systems, but virtually all electoral systems give a bonus in seats to the majority party (Rae 1971). In the present idealized two-party model, this tendency is called a "majoritarian" electoral system (and is modeled with $1<\rho<\infty)$. This type of system may foster governability, since the majority party is allocated a higher proportion of seats than the votes it receives, and one might also argue that such systems enhance competitiveness and minority representation, since the majority party advantage in the seats-votes relationship gets progressively smaller as the majority gets larger (see the two relatively steep and hence responsive curves in Figure 1 for $\rho=3$ and $\rho=8$ ). However, governability has other sources, and majoritarian electoral systems have other consequences (see Lijphart 1984, chap. 7). Winner-take-all electoral systems (with $\rho \approx \infty$ ), where a party with only slightly greater than half the vote receives all the seats statewide, fall at the other extreme. Here, responsiveness is maximized at the cost of minority representation and electoral reflection.

Representation thus spans unresponsive $(0<\rho<1)$, proportional $(\rho=1)$, majoritarian $(1<\rho<\infty)$, and winner-take-all $(\rho=\infty)$ electoral systems. By including unresponsive representation on the same continuum, in this way, this presentation thus significantly expands the notion of representation in King and Browning (1987). Note that since these seats-votes curves are sym- 
metric with respect to the parties, they all model different types of unbiased electoral systems.

These curves depict some of the many possible state-level electoral systems existing under geographically contiguous single-member districts. They are not drawn on the basis of any data, and none of these forms of representation are required by law. The specific model used to draw these figures is the bilogit functional form, introduced by King and Browning (1987). Under the bilogit form, and most other forms proposed for the relationship between seats and votes, the expected proportion of statewide Democratic seats is a function of statewide Democratic votes and some parameters:

$$
E(S)=f(V, \text { Parameters })
$$

In a familiar special case, this form $f(\cdot)$ is linear and the parameters are the intercept $(\alpha)$ and slope $(\beta)$ coefficients (see Tufte 1973; Schrodt 1981):

$$
E(S)=\alpha+\beta V
$$

However, a linear form is implausible, since expected seats could go below zero or above one, is not constrained to pass through the 0,0 and 1,1 points (which we know for certain), and for several other reasons described by King and Browning (1987).

I therefore turn to the full bilogit form:

$$
E(S)=\left\{1+\exp \left[-\lambda-\rho \ln \left(\frac{V}{1-V}\right)\right]\right\}^{-1}
$$

This special case of equation 1 may appear more complicated than the linear special case in equation 2 , but it is nearly as simple to use, has the same number of parameters, and is more theoretically appropriate. In the bilogit equation, the two parameters have distinct meanings: $\lambda$ is the partisan bias parameter. ${ }^{6}$ The equality $\lambda=0$ indicates an unbiased system; $\lambda>0$ refers to an electoral system that favors the Democrats, and $\lambda<0$ favors the Republicans. The parameter $\rho$ indexes the form of democratic representation. Once $\lambda, \rho$, and $V$ are set to specific numbers, the right-hand side of equation 3 reduces to a single number, the expected proportion of Democratic seats. Each of the graphs in the first column of Figure 1 was drawn by setting $\lambda=0$, to indicate the absence of partisan bias, setting $\rho$ at a value associated with a particular graph, and substituting in a range of values of $V$ between zero and one.

When the electoral system is biased toward one party or the other, this range of representational forms is not reduced, since representation and bias exist on separate dimensions and are modeled with distinct parameters. Instead, partisan bias appears in this model as asymmetry in the seats-votes curve-deviations

\footnotetext{
${ }^{6}$ The parameter $\lambda$ in this article is equivalent to $\ln (\beta)$ from King and Browning (1987).
} 
FIGURE 2

Forms of Representation with Bias $(\lambda=1.0)$

Seats-Votes Curves
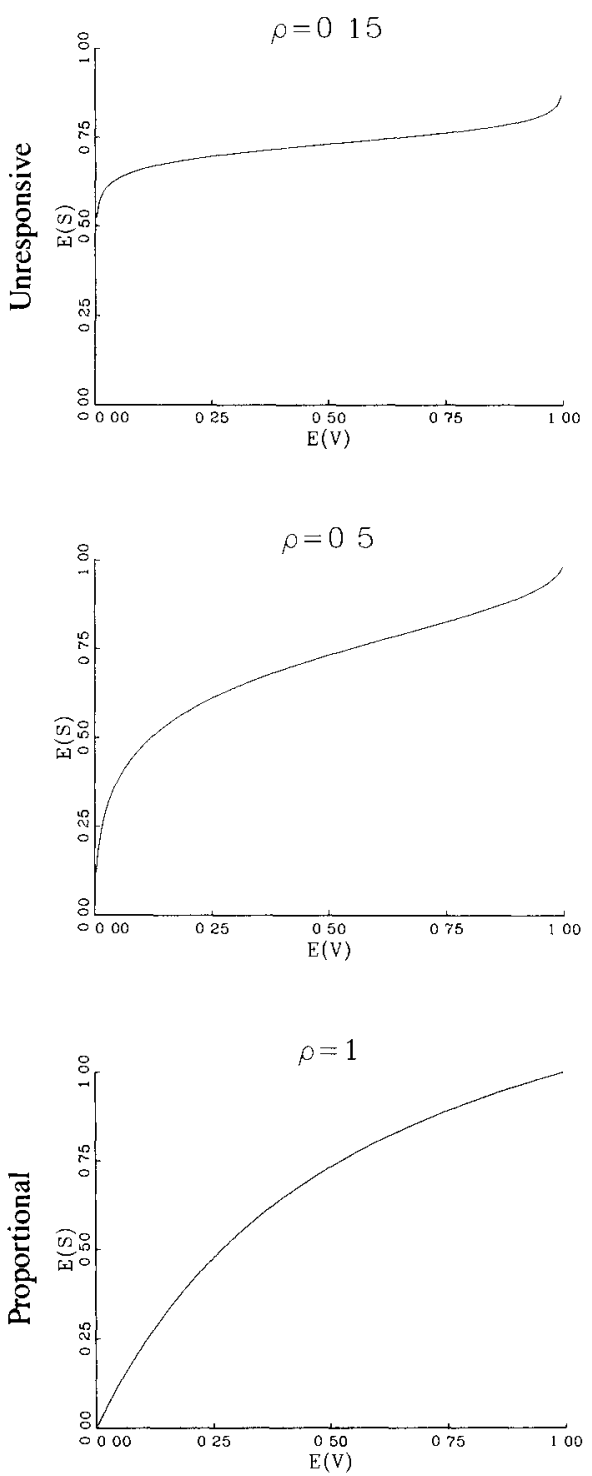

Mean Voter Preference Distributions
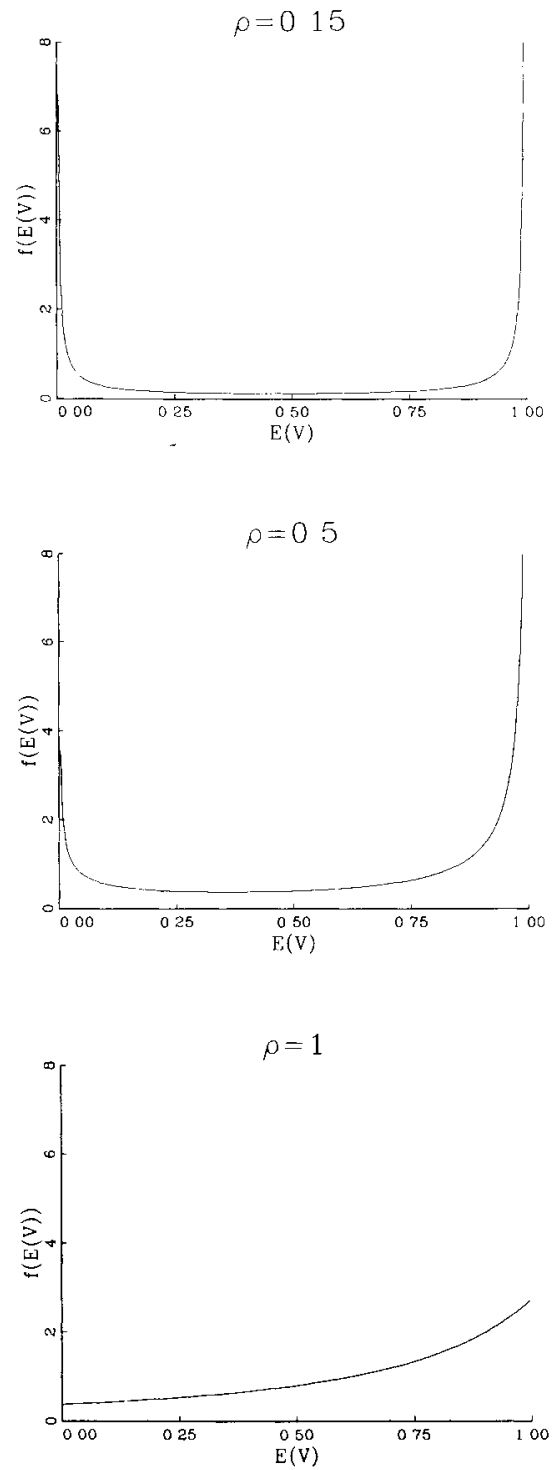
FIGURE 2 (cont.)

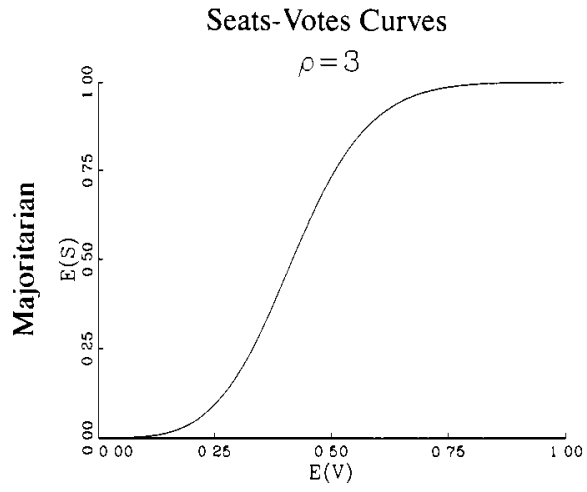

Mean Voter Preference Distributions
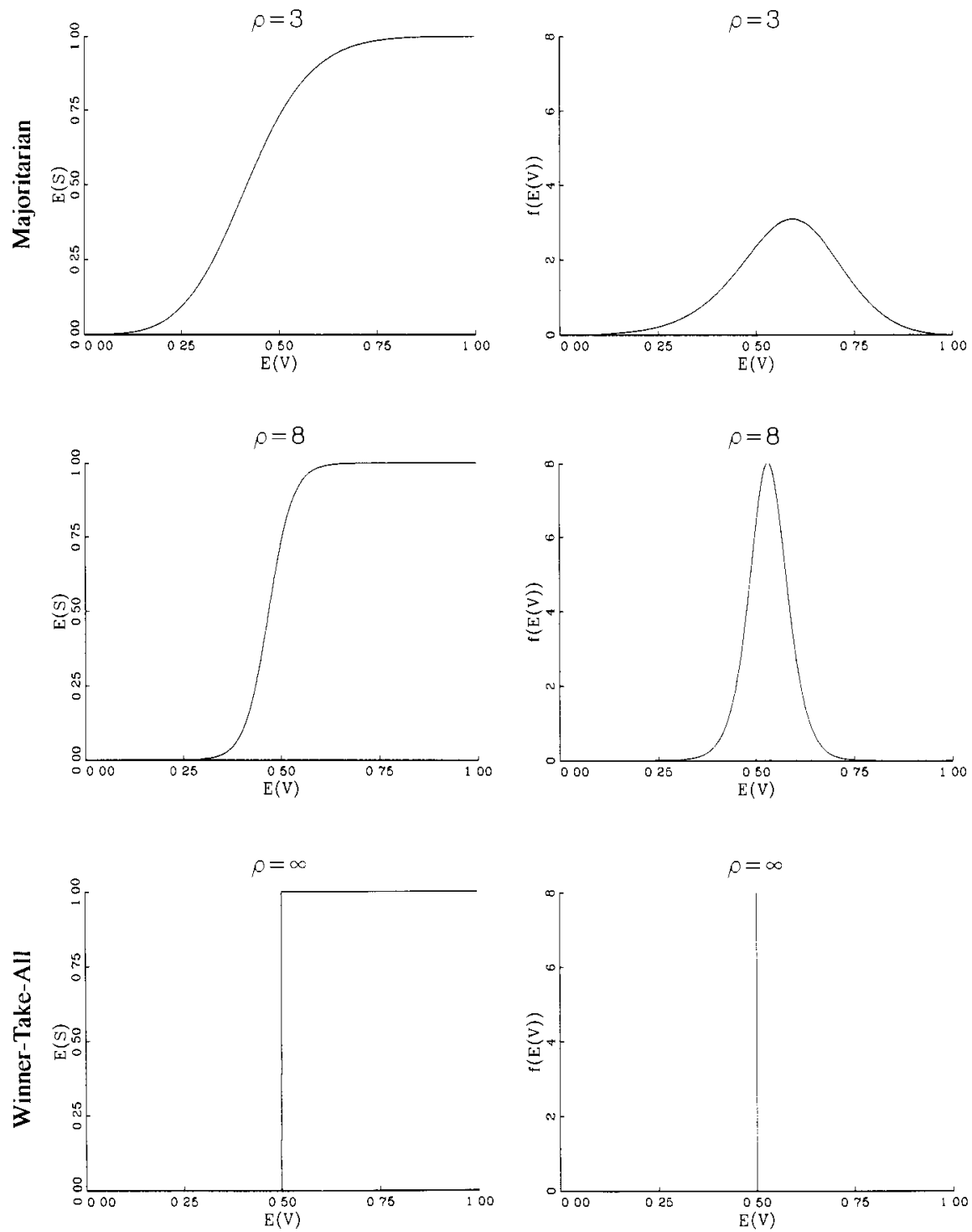
from a particular form of (symmetric) representation. The first column of Figure 2 redraws each of the curves from the first column of Figure 1 with $\lambda=1$ indicating bias favoring the Democratic party (please ignore the second column of both figures until the next section). For each, note how the Democrats would receive more seats for a given proportion of votes than the Republicans would be allocated if they had gotten the same proportion of votes.

Although partisan bias is introduced as a deviation from partisan symmetry, even biased seats-votes curves pass through the 0,0 and 1, 1 points. Except in cases of voter fraud, district-level results that are uniformly 0\% Democratic (or Republican) aggregate deterministically to the statewide level. For all other patterns of district-level results, the aggregation process produces a stochastic relationship.

\section{From Voter Preferences to the Seats-Votes Curve}

The bilogit form was used by King and Browning (1987) to estimate the partisan bias $\lambda$ and representation $\rho$ parameters with data from many elections. The basic idea was to plot statewide seat proportions by statewide vote proportions, with each point on the plot representing a single election. One then fit the bilogit form to these points to estimate $\rho$ and $\lambda$. This approach is useful for some purposes, but not for tracking changes in the parameters over time to assess the effects of redistricting or other factors.

In order to study short-term changes in $\rho$ and $\lambda$ both theoretically and empirically, a district-level model is necessary. By far the most common model of this sort is called uniform partisan swing; I describe this model and its relatively unrealistic assumptions in the first subsection. Following that, I derive a more sophisticated stochastic district-level model in the second subsection and introduce a much more general assumption for deriving the seats-votes curve in the final subsection.

\section{The Uniform Partisan Swing Model}

In order to derive a seats-votes curve from district-level electoral votes, some assumption needs to be made. The most widely used assumption in the literature is called "uniform partisan swing" and was introduced by Butler in 1951 (for recent applications, see Niemi and Deegan 1978, Gudgin and Taylor 1979, Niemi 1985, Niemi and Fett 1986, and many others). The assumption is that vote proportions in every district all move in lockstep, swinging back and forth in response to national or statewide electoral forces and without any random error or local factors to make them behave differently.

With this assumption one can draw a seats-votes curve from district-level information as follows: the first point plotted on the seats-votes curve is the actual election result. Then, one percentage point is added to the vote in each district and new hypothetical values for statewide seats and votes are calculated 


\section{FIGURE 3}

Seats-Votes Curve, Assuming Uniform Partisan Swing on the Logit Scale, Pennsylvania State Assembly, 1972

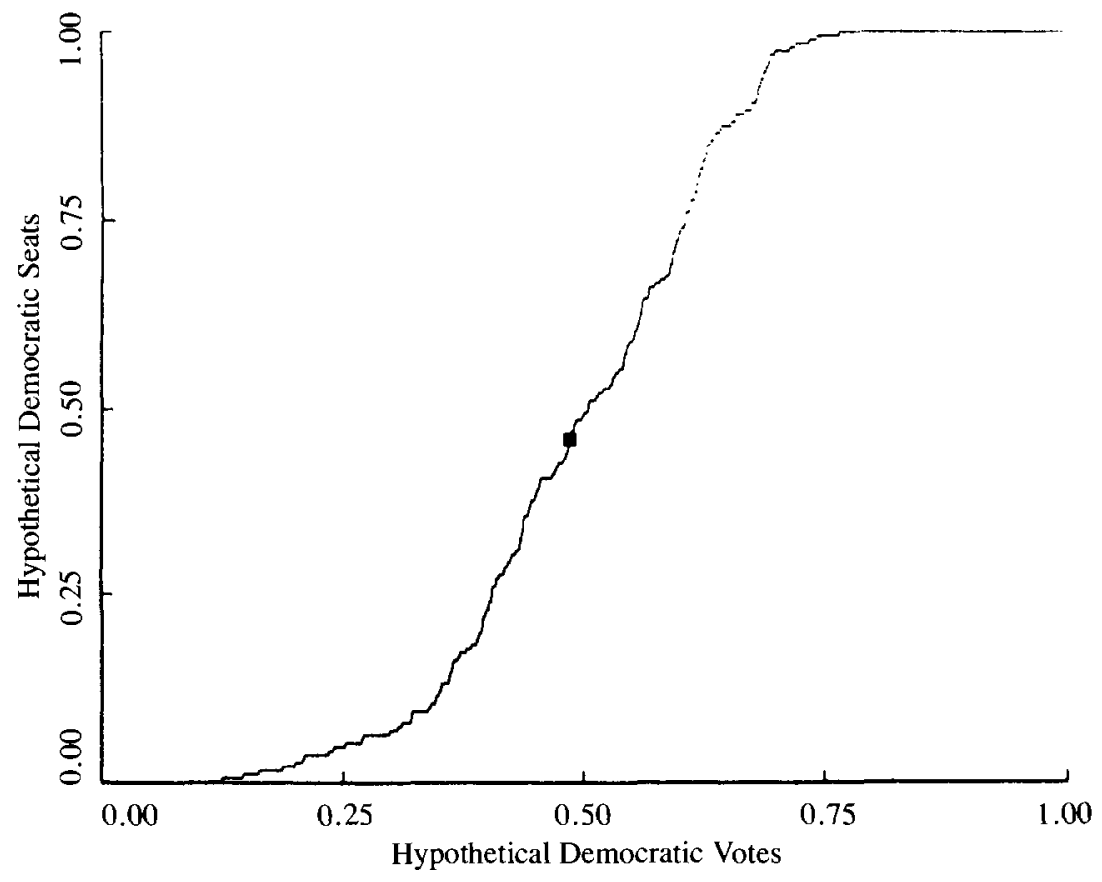

by aggregating these hypothetical district-level data. This procedure is repeated by continuing to add (or subtract) these hypothetical votes to each district in small increments until the entire curve is drawn.

One problem with the uniform partisan swing assumption is that it is internally inconsistent, since districts that already give lopsided victories for a candidate will go over $100 \%$ or below $0 \%$ of the vote when creating new hypothetical elections. However sensible uniform partisan swing might appear in the competitive region near $50 \%$, it is obviously incorrect at the extremes. Fortunately, we can make a simple modification of the assumption to preserve at least internal consistency. The modification allows districts to move uniformly on the logit scale - so districts with vote proportions near 0.5 will move nearly linearly, and districts close to the extremes will not go beyond the boundaries.

Figure 3 presents an example of a seats-votes curve drawn with the uniform partisan swing on the logit scale assumption. The small square denotes the actual statewide election result, and the rest of the line was drawn with the assumption. Although this approach does provide a reasonable starting point, permitting 
FIGURE 4

District-Level Electoral Swing, Pennsylvania State Assembly, 1972-74

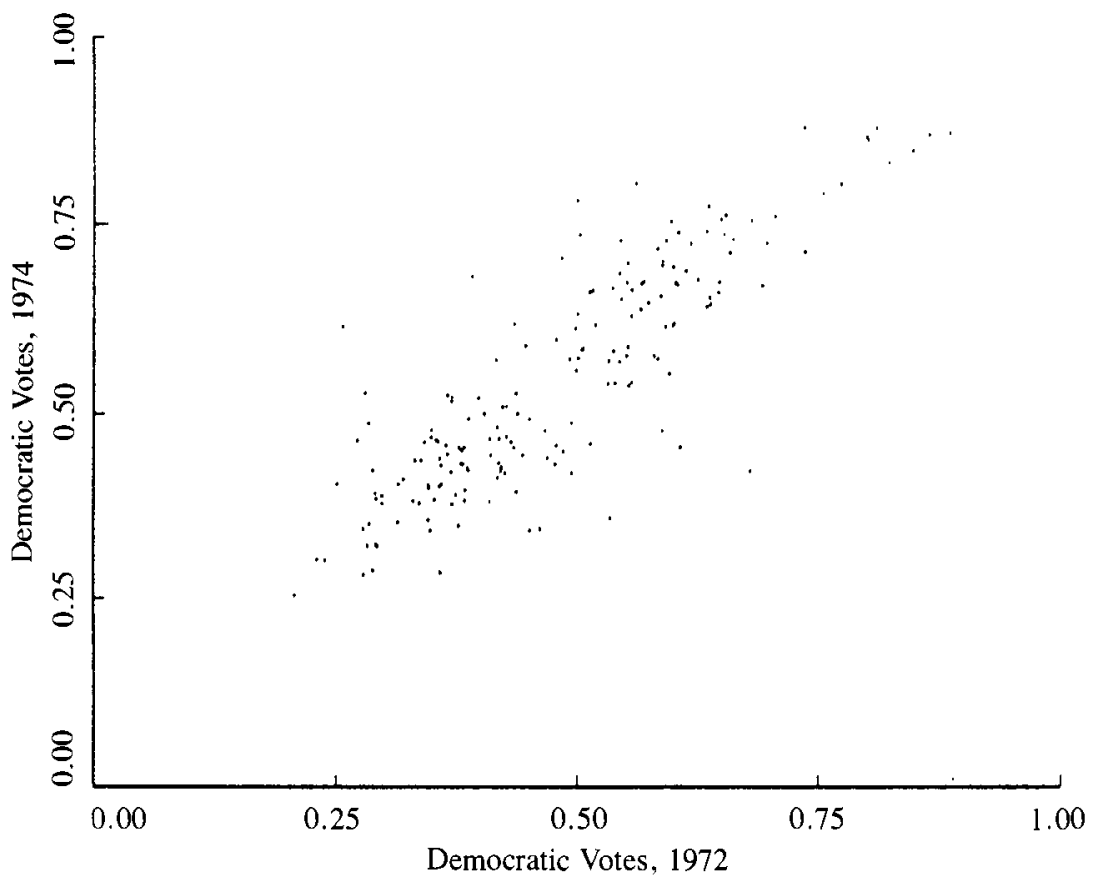

some estimates to be made that would otherwise be impossible, it also has several severe weaknesses. First, the assumption is empirically false. Tracking real districts from election to election reveals approximate uniform shifting, but always with some variability. Figure 4 provides an example of this interelection variability; graphs for other pairs of elections look similar, although some have more and some less variability. If the uniform partisan swing assumption held exactly, all of the points in Figure 4 would fall on a straight line. They do fall somewhat near a straight line, but the evidence for variability around this line is unambiguous. A more reasonable model should explicitly take this variability into account.

Furthermore, by assuming the absence of variability, all estimates of variation across repeated hypothetical elections, including standard errors, are zero. Since politics is hardly deterministic, this assumption should obviously be changed. Incorporating this variability will yield estimators with more desirable statistical properties, but it also will enable analysts to distinguish observed changes that are unique from those that reflect significant changes in the underlying electoral system. 


\section{Mean Voter Preference Distributions}

The first step to a more general assumption is an explicit probabilistic mechanism. The mechanism ensures that individual district vote proportions within a state are drawn randomly from some probability distribution rather than having to follow any particular deterministic pattern. Begin by letting $V_{1}$ be the proportion of citizens in a legislative district who would cast their ballots for a Democratic candidate at time 1 , which is generally the first election following a redistricting. ${ }^{7}$ The variable $V_{1}$ then varies across districts within a state. Since $V_{1}$ is an unobserved random variable, I hypothesize an underlying probability distribution, termed the mean voter preference distribution, from which an election in each district is randomly drawn. This is the point where stochastic variability is explicitly recognized: an unobserved "electoral system" is assumed, and even if this distribution remains constant and the same election were run again, observed electoral results will differ. These repeated elections will vary randomly around the true underlying electoral system. The assumptions we make later to derive the seats-votes curve will involve the underlying electoral system, rather than requiring the observed district-level vote proportions to follow any particular deterministic pattern.

The distribution chosen must be flexible enough to include cases where it is unimodal, to allow for competitive electoral systems with most districts having proportions near 0.5 ; bimodal, to allow for uncompetitive party systems with many successful incumbents in both parties; skewed, in the case of bias toward one of the parties; and combinations of these. Instead of this distribution, one could use a histogram of the proportion voting Democratic in each district across an actual state, but a model requires a mathematical formulation abstracting the key features of this histogram (i.e., bias and representation).

Choosing a particular probability density to model the distribution of mean voter preferences across districts is no trivial matter. Deriving one by making assumptions about individual voters, their spatial arrangement, or the process of redistricting would narrow the range of possibilities only negligibly for present purposes, as Quandt (1974) and Gudgin and Taylor (1979) demonstrate. Alternatively, one can choose an existing distribution which is flexible enough to handle most interesting cases. Unfortunately, none exist in the literature. ${ }^{8}$ I have therefore derived the single probability distribution of district-level votes that,

${ }^{7}$ Alternatively, time 1 could refer to any point after redistricting, but prior to the first election. Under this formulation we explicitly recognize that an electoral system exists at all points in time, even when it remains unobservable.

${ }^{8}$ Obvious choices include the Beta distribution or one of those developed for correlation coefficients. Only the Beta distribution allows for bimodality but is not flexible enough for present purposes (see Johnson and Kotz 1972). 
when aggregated to the statewide level, results in the bilogit seats-votes curve in equation 1. This new distribution encompasses a large variety of interesting cases that arise in this context. The distribution is defined on the interval $(0,1)$; special cases of it are unimodal, bimodal, peaked, uniform, skewed, and various combinations of these features.

Begin by assuming that mean preference for Democratic candidates at time $1\left(V_{1}\right)$ is distributed as the probability density in equation 4 :

$$
f_{V_{1}}\left(v_{1}\right)=\rho e^{\lambda}\left[e^{\lambda}+\left(\frac{v_{1}}{1-v_{1}}\right)^{\rho}\right]^{-2} v_{1}^{-(1-\rho)}\left(1-v_{1}\right)^{-(1+\rho)}
$$

This mean voter preference distribution has two parameters: $\lambda$, which indexes direction and degree of skewness, and $\rho$, which indexes peakedness (ranging from a single spike to extreme bimodality). Combinations of values of these parameters produce the flexibility seen in the examples drawn in the second columns of Figures 1 and 2 . On the basis of the analyses in the rest of this section, this distribution allows one to separate reliably the degree of partisan bias from the form of democratic representation in a district-level theoretical analysis in section 4 and empirical analysis in section 5 .

\section{Deriving the Expected Seats-Votes Curve}

From this distribution of district means, I now show how to derive the expected seats-votes curve and observe how representation and bias operate.

First, the expected value of this distribution $\left[E\left(V_{1}\right) \equiv \mu_{1}\right]$ is the average of all the district means - the statewide proportion of voters preferring their respective Democratic candidate. Second, the expected proportion of seats allocated to the Democrats $\left[E\left(S_{1}\right)\right]$, as a function of $\mu_{1}$ (and $\rho$ and $\lambda$ ), is equal to the area under the $V_{1}$ curve where the Democrats receive a majority. This is the area to the right of 0.5 Democratic votes.

Given a particular probability density describing voter preferences across the state, we use standard methods to calculate the expected votes and expected seats; these are the respective proportions of votes and seats that we would observe on average across a large number of hypothetical replications of essentially the same election. Calculating the mathematical expectation-the mean of the distribution-provides expected votes $\left[E\left(V_{1}\right) \equiv \mu_{1}\right]$. Since the total area under a probability distribution is always 1.0 , the area under the curve to the right of $V_{1}=0.5$ is equal to the expected proportion of those districts that elect a Democratic candidate, $E\left(S_{1}\right)$. With $E\left(V_{1}\right) \equiv \mu_{1}$ and $E\left(S_{1}\right)$ providing the coordinates, we draw a single point on the expected seats-votes curve.

In order to draw other points on the expected seats-votes curve, the distribution of voter preferences must be systematically changed in some way. This requires an assumption about how the underlying electoral system will change in future elections. Uniform partisan swing is one possible assumption. Fortu- 
nately, this method enables one to relax the most unrealistic features of this assumption.

In general, $\lambda$ and $\rho$ fix the shape of the distribution. Some of the specific shapes are given in the second column of Figures 1 and 2, along with the values of $\lambda$ and $\rho$. Under one possible assumption, as the mean of the district vote proportions, $\mu_{1}$, varies, the shape of the probability density remains unchanged; this is equivalent to assuming that the values of $\lambda$ and $\rho$ remain the same as $\mu_{1}$ changes. Thus, when some national force impinges on all districts in the state, we no longer assume that the districts move together in lockstep. Instead, as the expected value (mean) shifts, only the shape of the distribution of district vote proportions must remain the same. Individual districts are free to vary randomly within this shape, with or without uniform partisan swing. Given this additional assumption, each shift of the mean, and thus the entire distribution, alters the value of $\mu_{1}$ (mean votes) and also yields a corresponding area to the right of 0.5 (mean seats); these serve as coordinates for an additional point on the seats-votes curve. For a given distribution, one continues to calculate points until the entire expected seats-votes curve is derived.

Figure 5 portrays an example of this assumption where the shape of the distribution of voter preferences is unbiased $(\lambda=0)$ and responsive $(\rho=4)$. This distribution appears on the right side of the figure for mean Democratic votes $\left(\mu_{1}\right)$ at $0.3,0.4$, and 0.6 . To calculate the proportion of seats allocated to the Democratic party that corresponds to each of these statewide proportions of Democratic votes, I calculate the area under the respective distribution to the right of 0.5 (colored in black in the figure). The lowermost point on the seatsvotes curve (also in Figure 5) was plotted from 0.3 mean Democratic votes $\left(\mu_{1}\right)$ and 0.03 mean Democratic seats (based on the area under the distribution to the right of 0.5 ). The next point was plotted at $\mu_{1}=0.4$ and mean seats 0.16 , and the final point at $\mu_{1}=0.6$ and mean seats 0.84 . In a similar manner, the entire set of points $\left(0<\mu_{1}<1\right)$ were calculated, and the complete seats-votes curve was drawn (see the smooth seats-votes curve in Figure 5).

This fixed-shape assumption can be weakened still further, since we have thus far constrained the degree and direction of partisan bias $(\lambda)$ and form of democratic representation $(\rho)$ to be unchanged as the statewide mean of voter preferences $\left(\mu_{1}\right)$ varies. ${ }^{9}$ I therefore make the more general and even less restrictive assumption that bias and representation may vary with the mean of the voter preference distribution and constrain only the area, not the shape, to change in a consistent way as $\mu_{1}$ varies. Intuitively, this allows (but does not require) the three distributions in Figure 5 to be different shapes, as long as the area to each side of the 0.5 line remains equal to the areas shown in Figure 5 for these three

${ }^{9}$ In fact, this latter assumption must be false in the extremes, for as $\mu_{1}$ approaches 0 or 1 , the distribution indicates that some districts have Democratic candidates receiving more than $100 \%$ or less than $0 \%$ of the votes. 
FIGURE 5

From Mean Voter Preference Distribution to Aggregate Seats-Votes Curve

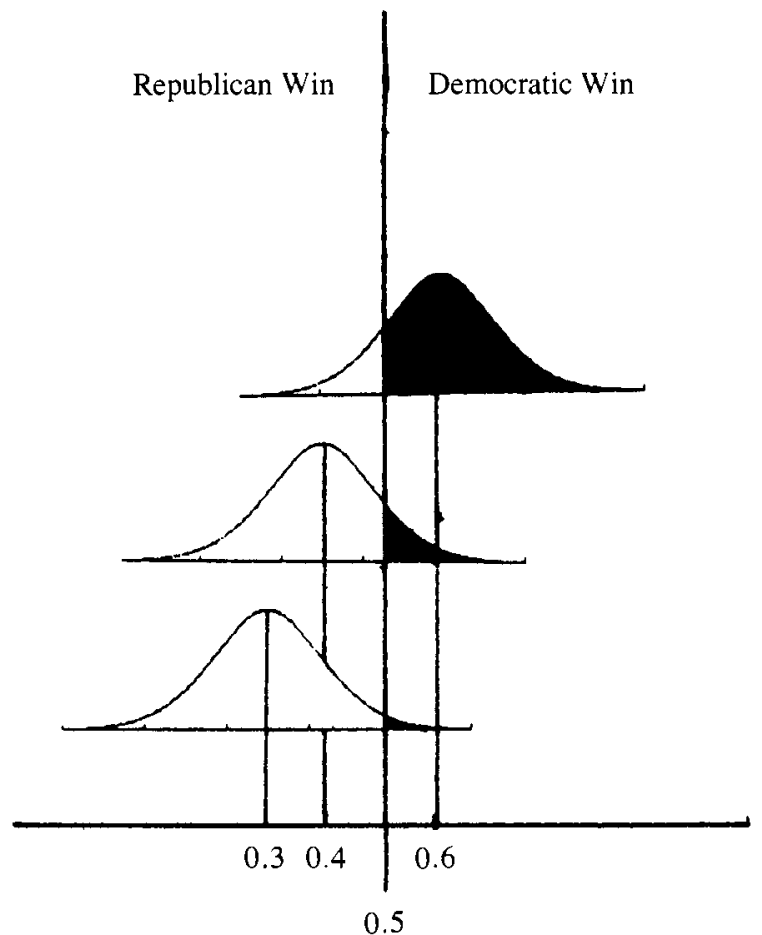

Proportion Democratic Votes

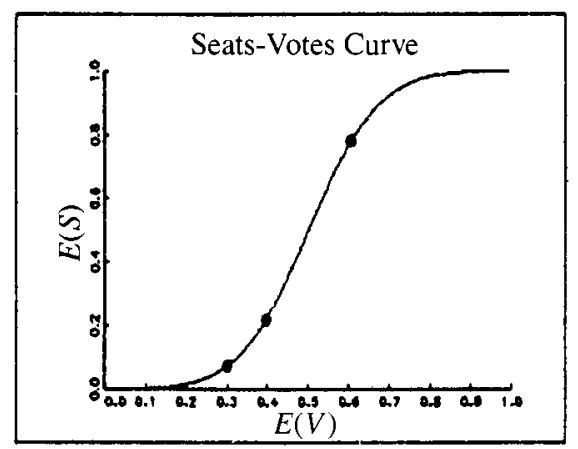


distributions. Mathematically, this assumption is expressed by using the standard tool for calculating the area under a curve-integration: ${ }^{10}$

$$
E\left(S_{1} \mid \mu_{1}\right)=\int_{0}^{\mu_{1}} f_{V_{1}}\left(1-\mu_{1}\right) d \mu_{1}
$$

where the integral is taken over $\mu_{1}$ instead of $V_{1}$ in order to properly constrain the area under the curve as the mean changes. For this equation to hold approximately, the mean voter preference within a district must have some level of inertia - something reasonably assured due to the stability of party identification and the power of incumbency. Unfortunately, since this assumption is about a probability distribution that changes at each point in time, and from which we observe only one election at a time, it would be difficult to verify by empirical investigation. Fortunately, it is considerably less restrictive than uniform partisan swing, incorporating plausible systematic changes in the distribution, as well as allowing for random variability.

By substituting equation 4 , the probability density function, into equation 5 and integrating, I use this improved assumption to derive the time 1 seats-votes curve:

$$
\begin{aligned}
E\left(S_{1}\right) & =\int_{0}^{\mu_{1}} f_{V_{1}}\left(1-\mu_{1}\right) d \mu_{1} \\
& =\left[1+e^{-\lambda}\left(\frac{1-\mu_{1}}{\mu_{1}}\right)^{\rho}\right]^{-1}
\end{aligned}
$$

The second line of this equation is an algebraic simplification of the original bilogit form in equation 3, with $\mu_{1} \equiv V .{ }^{11}$ As such, $\rho$ and $\lambda$ can be interpreted as before in Figures 1 and 2 . In fact, each mean voter preference distribution portrayed in these figures gives rise to a corresponding seats-votes curve drawn beside it through the use of the new and more general assumption in equation 6 . The $\rho$ and $\lambda$ parameters are the same for both in each pair. ${ }^{12}$

Figure 1 shows how one type of bimodal mean voter preference distribution $(0<\rho<1)$ leads to an unresponsive seats-votes curve. A bimodal distribution occurs when both parties have many noncompetitive districts or very popular incumbents. The seats-votes curve is unresponsive in such cases because the

${ }^{10}$ This integral is only an approximation if $\lambda \neq 0$.

${ }^{11}$ In order to go the other way, from a given statewide seats-votes curve to the district-level probability distribution of votes, one would differentiate.

${ }^{12}$ Intuition about this functional form can be developed through the graphs presented in the text or direct mathematical analysis. For the latter, consider that this form is the inverse of the logit of votes embedded within another logit. As such, the equation can Iook like a Iogit or an exaggerated or dampened form of a logit. The inverse logit and logit can even cancel out, resulting in a linear relationship. (For other purposes one could use this functional form to test for the linear probability versus logit model, as this form embeds both in a more general model; see Achen 1986). 
division of seats between the parties does not change unless voter preferences dramatically change. With smaller swings, the incumbents get smaller or larger majorities, with partisan turnover occurring only in the few marginal seats. Since the early 1970s, scholars of congressional elections have been interested in the problem of vanishing marginals - the recent tendency of most districts to become less competitive. Equation 4 provides an explicit model of this phenomenon by letting voter preferences (with $\rho<1$ ) follow a bimodal distribution. Congressional scholars have posited many possible causes for this trend toward bimodality. ${ }^{13}$ Below, I explicitly model the process by which incumbency can lead to bimodality and, hence, unresponsiveness and also show how the recent increased variation in partisan swing (Jacobson 1987) can have a similar effect.

When voter preferences are uniformly distributed across districts $(\rho=1)$, de facto proportional representation results. A unimodal distribution $(1<\rho<$ $\infty$ ) results in a majoritarian electoral system because larger numbers of marginal districts make seat allocation more responsive to small changes in citizen preferences.

The mean voter preference distributions in the second column of Figure 2 are all skewed, with the bulk of the area over the Democratic end of the continuum. When these are mapped onto a seats-votes curve with equation 6 , skewness in the distribution becomes partisan bias in the seats-votes curve.

Even assuming that individual voters do not change their preferences, the distribution of voter preferences across districts is altered by redistricting. Those who control the redistricting process-or, equivalently, determine the values of $\rho$ and $\lambda$-may be partisan or bipartisan legislators or statewide elected officials, bipartisan or nonpartisan redistricting commissions, or state or federal courts. This control is constrained by factors such as natural and political geography. In addition, districts must be contiguous, have roughly equal numbers of inhabitants, and usually must be compact. Citizens with a particular political preference do not always live in locations convenient to those overseeing redistricting. The latter may also have to contend with local political elites, forge compromises in state legislatures or with governors of different political parties, satisfy exist-

\footnotetext{
${ }^{13}$ In congressional elections the two modes are closer to 0.5 than in Figure 2. The possible causes of this trend toward bimodality in congressional elections may include an increase in the electoral advantage of incumbency due to constituency service (Fiorina 1977); bipartisan gerrymandering, where in states with split party control cross-party deals are struck so that the lines drawn protect incumbents of both parties (Mayhew 1971; Tufte 1973); partisan gerrymandering, where states with unified party control give the minority party a few seats with very high margins of victory and most seats to themselves with similar high margins (Owen and Grofman 1988); a decline in the influence of party identification on mass voting behavior (Erikson 1972; Burnham 1974), or some combination of these factors. Somewhat more unlikely, but still theoretically possible, causes of increasing unresponsiveness are geographically located clusters of like-minded voters tending to be larger than the size of congressional districts (Gudgin and Taylor 1979) or an increase in the political homogeneity of congressional districts.
} 
ing incumbents or prospective candidates, or include specific landmarks or geographical areas in a particular legislator's district. ${ }^{14}$

Partisan gerrymanderers are likely to try to bias the system in their own party's favor. If their majority is large, they might also attempt to insulate their party by creating an unresponsive system and bimodal voter preference distribution ( $\rho<1$; see Owen and Grofman 1988). However, successful partisan gerrymanderers will also try to release the grasp that opposition party incumbents have on their districts, thus leading to a more responsive electoral system. In this case a relatively responsive party system (large $\rho$ ) would be ideal, in that it would facilitate winning back seats from vulnerable incumbents or claiming open seats vacated as incumbents retire. ${ }^{15}$

Districting plans may also be drawn by bipartisan groups, particularly when the governor and both houses of the state legislature are not controlled by the same party. In some states, bipartisan redistricting commissions are created by provisions in the state constitution. In these situations redistricting plans are compromises worked out among incumbents of different parties. The result should be redistricting with no partisan bias or, minimally, no change in bias. In addition, deals between the political parties will likely benefit the incumbents of both parties considerably, resulting in an even more bimodal voter preference distribution and, hence, a less responsive electoral system.

Strictly nonpartisan groups may also be responsible for redistricting. For example, courts with no partisan predispositions may draw the maps themselves or may commission special masters to redistrict under strict court guidelines. Although many of these are de facto partisan or bipartisan plans (Dixon 1968), a few are truly nonpartisan. While not as common as partisan or bipartisan redistricting, this case is of considerable theoretical interest. These circumstances should lead to very small bias $(\lambda \approx 0)$ and a more responsive, majoritarian electoral system (large $\rho$ ).

\section{Theoretical Analysis}

In order to evaluate precisely how redistricting alters the distribution of mean voter preferences, I now incorporate partisan swing and incumbency vot-

${ }^{14}$ Despite these countervailing constraints, most would assume that individuals in charge of redistricting influence representation and bias and, in my notation, effectively choose values of $\rho$ and $\lambda$, thereby determining the distribution of voter preferences across districts. Below, this assumption is borne out empirically, insofar as I find that redistricting does have predictable effects in the short run.

${ }^{15}$ Furthermore, many of the states that exercise partisan control of the redistricting process have competitive party systems, since redistricting is of little consequence in one-party states. These competitive party states are also likely to have electoral systems that are relatively responsive and hence have larger values of $\rho$. Glazer, Grofman, and Robbins (1987, 702-04) give four additional reasons why "redistricting plans in the $1970 \mathrm{~s}$... did not resemble the classic prescription for optimal partisan gerrymandering." 
ing effects in a model of change from time 1 to time 2 . Time 2 is coincident with an election-either the first post-redistricting election, if time 1 was prior to the first election, or the second election, if time 1 was at the first election. In the first subsection, I introduce both incumbency and partisan swing as fixed effects. After that, I allow the effect of partisan swing to vary randomly across districts within the state. The object in both sections is to discover how democratic representation and partisan bias are affected by these features of American politics that occur independently of and following redistricting.

\section{Incumbency and Partisan Swing}

The first model takes partisan swing, denoted as $\varepsilon$, to be fixed over districts. Incumbency is indexed by $\gamma$. Partisan swing can favor either the Democrats $(\varepsilon>$ $0)$, the Republicans $(\varepsilon<0)$, or, on average, neither party $(\varepsilon=0)$. National factors (a presidential election or midterm congressional election), statewide factors (a popular gubernatorial candidate), a political scandal, or an important local or regional issue account for some of these partisan swings. ${ }^{16}$

Incumbency (with $\gamma>1$ ) is modeled to have the predicted effect of pushing a district with a Democratic victory at time $1\left(V_{1}>0.5\right)$ toward favoring the Democrats and pushing a district with a time 1 Republican victory $\left(V_{1}<0.5\right)$ toward favoring the Republicans, even more at time 2 than time 1 . Incumbency is also assumed to affect each district in a similar manner. Relaxing this assumption (i.e., including a dichotomous variable and allowing some but not all districts to have incumbents) would not materially alter the conclusions.

In order to incorporate partisan swing $(\varepsilon)$ and incumbency $(\gamma)$ effects in a model with representation $(\rho)$ and bias $(\lambda)$, we need to study how the distribution derived above changes from election to election. The first task is to formulate a model that has the Democratic vote proportion at time $2\left(V_{2}\right)$ varying as a function of Democratic votes at time $1\left(V_{1}\right)$ and the partisan swing and incumbency parameters. Many functional forms would give $\varepsilon$ and $\gamma$ the proper interpretation, but a particularly convenient form for a model of district-level electoral change is the one we used in equation 5 for a different purpose: ${ }^{17}$

$$
V_{2}=\left[1+e^{-s}\left(\frac{1-V_{1}}{V_{1}}\right)^{\gamma}\right]^{-1}
$$

${ }^{16}$ In this version of the model, partisan swing is assumed to affect all districts in the state in a similar manner. This initial model is also somewhat more sophisticated, since it allows a district with mean Democratic voter preference of, say, 0.99 and one of, say, 0.50 to respond differently to a swing toward the Democrats (otherwise the mean proportion favoring the Democrats in the first district would be greater than 1.0, an impossibility, or would unnecessarily restrict swing in the second). This model should not be confused with the assumption in equation 5 , which does not refer to real change over time.

${ }^{17}$ Many other assumptions for the form of equation 7 lead to similar substantive results. Additionally, the model of change in equation 7 can include an additive disturbance, with mean zero and appropriate distributional assumptions, without changing any of the results below. 
In this formula $V_{2}$ is larger when $V_{1}$ is larger. Without any partisan swing $(\varepsilon=0)$ or incumbency effect $(\gamma=1)$, this form has Democratic votes at time 2 equaling Democratic votes at time 1 :

$$
V_{2}=\left[1+e^{-0}\left(\frac{1-V_{1}}{V_{1}}\right)^{1}\right]^{-1}=V_{1}
$$

With some incumbency effect $(\gamma>1)$, district parties winning at time 1 receive a bonus at time 2; the larger $\gamma$ is, the larger the bonus. Unlike incumbency effects this functional form models partisan swing to affect all districts in the same direction: a Democratic swing $(\varepsilon>0)$ helps Democratic candidates (whether they win or lose at time 1) in every district and a Republican swing $(\varepsilon<0)$ helps all Republicans.

Given the mean voter preference distribution and corresponding expected seats-votes curve introduced in the last section to apply to time 1 , and the model of electoral change from time 1 to time 2 in equation 7, no further assumptions are necessary to derive the expected seats-votes curve for time 2. Appendix A demonstrates how to use the methodology of stochastic modeling to derive the time 2 results and proves that the time 2 mean voter preference distribution is as follows:

$$
\begin{aligned}
f V_{2}\left(v_{2}\right)= & \left(\frac{\rho}{\gamma}\right) e^{\left(\lambda+\varepsilon^{(\rho(\gamma)}\right.}\left[e^{(\lambda+\varepsilon \rho / \gamma)}+\left(\frac{v_{2}}{1-v_{2}}\right)^{(\rho / \gamma)}\right]^{-2} \\
& \times v_{2}^{-(1-\rho / \gamma)}\left(1-v_{2}\right)^{(1+\rho / \gamma)}
\end{aligned}
$$

and the corresponding expected seats-votes curve is

$$
E\left(S_{2}\right)=\left[1+e^{-(\lambda+\varepsilon \rho / \gamma)}\left(\frac{1-\mu_{2}}{\mu_{2}}\right)^{(\rho / \gamma)}\right]^{-1}
$$

The relationship between the seats-votes curves and between the mean voter preference distributions at times 1 and 2 elucidates the effects of partisan swing and incumbency voting on democratic representation and partisan bias. The general mathematical forms of the time 1 and time 2 seats-votes curves (equations 6 and 10) and mean voter preference distributions (equations 4 and 9) remain unchanged. However, the representation parameter changes from $\rho$ in the time 1 equation to $\rho / \gamma$ in time 2 , and the partisan bias parameter changes from $\lambda$ in time 1 to $(\lambda+\varepsilon \rho / \gamma)$ in time 2 . Since only the parameters, and not the form of these distributions, have changed, the parameters have the same interpretation as in Figures 1 and 2; the only difference is that both now have several components. For example, the new representation parameter, $\rho / \gamma$, means that time 1 representation $(\rho)$ is reduced by the magnitude of the incumbency effect-so that the allocation of legislative seats is less responsive to changes in citizen votes. In addition, three interesting results emerge from this model for partisan bias at time 2 . 
First, in the absence of partisan swing $(\varepsilon=0)$, partisan bias remains unchanged since time 2 representation reduces to that in time $1:(\lambda+\varepsilon \rho / \gamma)=$ $(\lambda+0 \rho / \gamma)=\lambda$. This result holds regardless of the form of time 1 representation or the extent of any incumbency effect.

Second, since $\rho / \gamma$ is always positive, partisan bias always changes from time 1 to time 2 in the direction of partisan swing. For example, for any degree of bias in time 1, a swing toward the Republicans after that time results in a system more biased toward the Republicans (or less biased toward the Democrats). Since the distribution of votes gives positive probability only for intervals of votes between zero and one, partisan swing in any direction must skew the mean voter preference distribution. Skewness, in turn, produces additional bias in the expected seats-votes curve.

Finally, the influence of partisan swing ( $\varepsilon$ ) on time 2 partisan bias $(\lambda+$ $\varepsilon \rho / \gamma)$ is dependent on the form of representation at time $2(\rho / \gamma)$. For example, suppose $\rho / \gamma$ is greater than one. In other words, time 1 representation is majoritarian and a relatively small incumbency effect occurs. ${ }^{18}$ The consequence of this relatively responsive system at time 2 is that the effect of partisan swing has an exaggerated effect on partisan bias. Conversely, when $\rho / \gamma<1$, the electoral system is unresponsive. This might occur either with an unresponsive system at time 1 and an incumbency effect of any size or with a large incumbency effect and any form of time 1 representation. As a result of this situation, legislative seats are unresponsive to citizen votes. In this situation even a large partisan swing against the favored party is unlikely to have a very large effect on time 2 partisan bias.

\section{Random Partisan Swing}

In the foregoing analysis, partisan swing is a fixed parameter, affecting all districts uniformly. This is appropriate if the factors producing the swing are the result of national or statewide factors. However, in some states and at some times, partisan swing is likely to be more variable across districts. For example, in extremely heterogeneous states, the assumption of all districts reacting in similar ways or even in the same direction is implausible. In many states people in urban areas may respond to political events with precisely opposite opinions to those in rural areas. Random partisan swing should also be more prevalent in states without strong party systems.

Accordingly, in this section, I take the partisan swing parameter $(\varepsilon)$ to be a random variable across districts instead of a constant. This formulation necessitates a revised stochastic model, incorporating an assumption about the way $\varepsilon$ is distributed, in a probabilistic sense, across districts.

\footnotetext{
${ }^{18}$ In theory $\rho / \gamma>1$ could also occur in other systems with reverse incumbency effects-where people vote against incumbents-but this is unlikely in practice.
} 
Since the interpretation of $\varepsilon$ is symmetric about zero, the probability density should also be symmetric, but with parameters for the mean and variation about the mean. I assume, for simplicity, that $\varepsilon$ varies according to a Uniform distribution on the interval $\tau-\theta$ to $\tau+\theta \cdot{ }^{19}$ In this distribution, $\varepsilon$ has a mean of $E(\varepsilon) \equiv \tau$, with $\theta>0$ a measure of variation around $\tau$. As $\theta$ approaches zero, this distribution collapses into a spike over $\tau$, where $\varepsilon$ (now equal to $\tau$ ) is a fixed parameter again. In general, $\varepsilon$ is now a random variable with mean $\tau$ and dispersion $\theta$.

Given the time 1 mean voter preference distribution and the assumption about how time 2 vote proportions depend on time 1 votes, incumbency, and constant partisan swing effects, the methods of stochastic modeling (in Appendix A) permitted the derivation of a new time 2 distribution and corresponding expected seats-votes curve. By making only one additional assumption-that $\varepsilon$ is a uniformly distributed random variable - we can derive a new time 2 distribution and expected seats-votes curve. Appendix B demonstrates how to use the methods of stochastic modeling techniques to derive these new results.

The new time 2 mean voter preference distribution and corresponding expected seats-votes curve appearing in Appendix B are somewhat more difficult to interpret than the results in the preceding section, since the mathematical forms of these equations are considerably more complex. However, one can still ascertain how the form of democratic representation and the degree and direction of partisan bias change in these equations. Through graphing and some direct mathematical analysis, several interesting points emerge. First, with small variation in partisan swing across a state $(\operatorname{small} \theta)$, these equations operate quite similarly to equations 9 and 10 in the last section, respectively. The mean of partisan swing $(\tau)$ plays roughly the same role as time 1 partisan bias $(\lambda)$. Time 1 representation $(\rho)$ and incumbency $(\gamma)$ also have similar effects.

Variations in partisan swing across districts, however, have very different effects in these equations: the more partisan swing varies across districts, the less responsive legislative seats are to changes in citizen votes. When partisan swing has similar effects on all districts in a state-as, for example, in relatively homogeneous states or those with very competitive party systems - the proportion of seats allocated to a party is considerably more responsive to small changes in aggregate voter preferences.

These effects are illustrated in Figure 6. The two graphs in the first row are

${ }^{19}$ I also tried the Normal and Logistic probability densities, but these made the analysis below analytically intractable. With numerical integration I was able to verify that the substantive results are quite similar to those presented in the text. I therefore stick to the simpler uniform density.

One should not confuse the procedure in this section with Butler's (1951) method of deriving the seats-votes curve. The latter is misnamed "uniform partisan swing" (it should really be called "constant partisan swing"), but it is an assumption used for a purpose completely different from the dynamic model in this section. 
FIGURE 6

Voter Preference Distributions with Random Partisan Swing
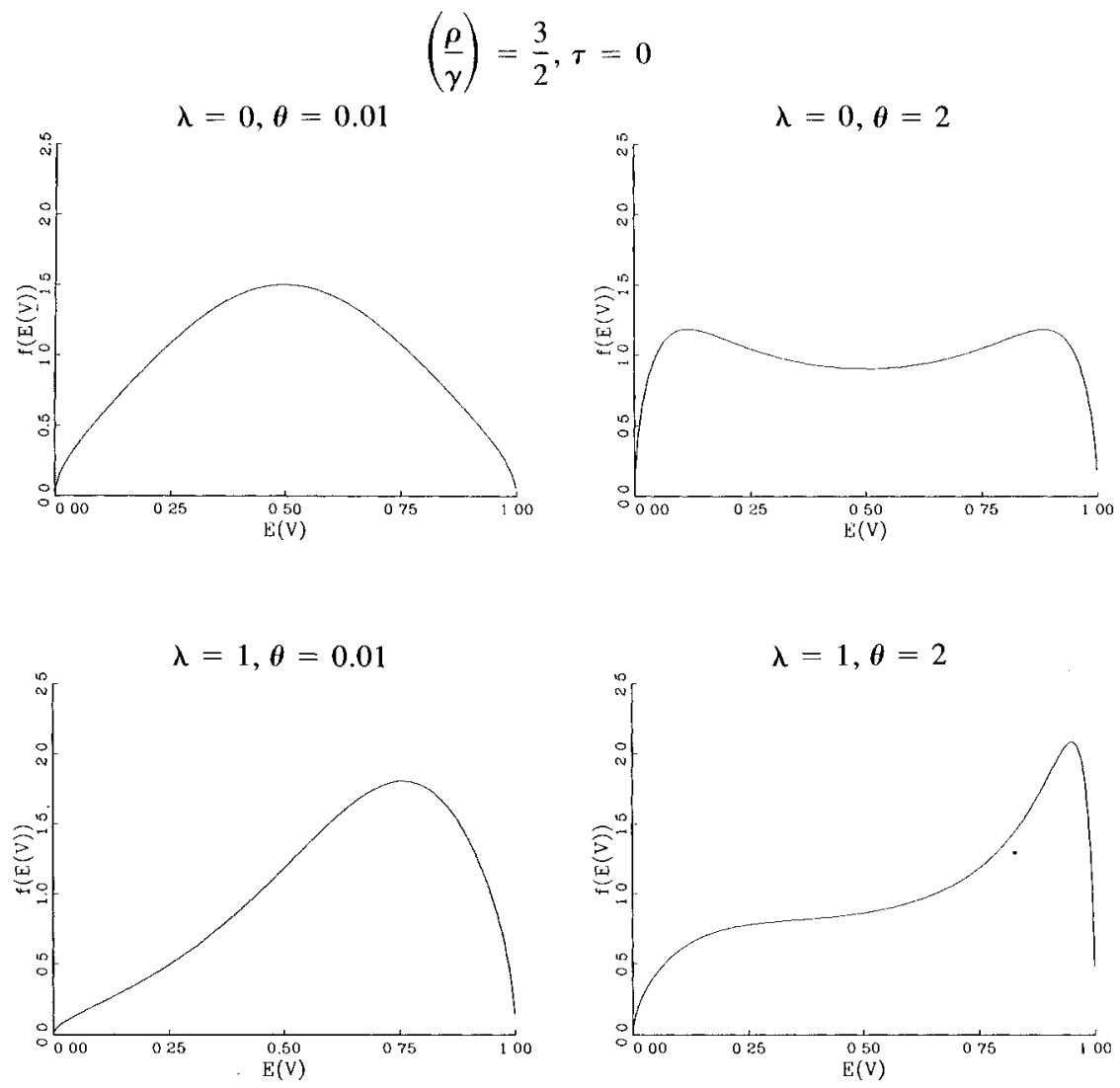

drawn with no bias or mean partisan swing in time 1 . Since $\rho / \gamma$ is greater than 1 , the curve on the top left (with a small variation in partisan swing, $\theta=0.01$ ) is unimodal, indicating a relatively steep majoritarian seats-votes curve (not pictured). The graph at the top right has all parameters set equal to those in the graph at the top left, except that it allows for more variation in partisan swing $(\theta$ $=2.0$ ). This changes the unimodal distribution into a bimodal distribution, essentially depressing the middle of the range of the distribution and hence making the electoral system unresponsive. The two graphs in the second row are drawn with bias favoring the Democrats; the effect of $\theta$ is essentially the same in this instance, making the biased curve somewhat less responsive as well. ${ }^{20}$

${ }^{20}$ This result suggests that the list of possible causes for declining competitiveness in congressional elections enumerated in note 13 is incomplete. The mean voter preference distribution can 


\section{Summary of Theoretical Results}

The stochastic model developed above provides a precise and flexible formalization of democratic representation and partisan bias and clarifies the very important distinctions between these concepts. As the foregoing analysis demonstrates, the concepts of partisan swing and incumbency voting from the congressional elections literature have determinate effects on representation and bias, concepts from the seats-votes literature. Incumbency reduces the responsiveness of the electoral system, whereas partisan swing affects whether the system is biased toward one party or the other. Incumbency and other causes of unresponsive representation also reduce the effect of partisan swing on current levels of partisan bias. Finally, in states where partisan swings are relatively constant across districts - such as those with highly competitive party systemsthe allocation of legislative seats to political parties after elections is likely to be much more responsive to changes in citizen votes. When partisan swing is more variable across districts, responsiveness declines.

\section{Empirical Analyses}

In Davis v. Bandemer (478 U.S.[1986]), the U.S. Supreme Court declared political gerrymandering justiciable for the first time. Particularly since this case, and the district court case leading to it (Bandemer v. Davis, 603 F. Supp. 1479 [S.D. Ind. 1984]), scholars of redistricting have put considerable effort into deriving measures of bias on the basis of one or relatively few election years (see, e.g., Grofman 1985a; Cain 1985b; Niemi 1985; Backstrom, Robins, and Eller 1978). Although many creative solutions have been proposed, the method introduced here derives from an explicit formal model using well-accepted statistical theory.

Although the method, described below, could be applied to any two-party electoral system, I illustrate the potential of this estimator with an application to U.S. state legislatures. The analysis that follows is not meant as an empirical test of the model, only as an illustration of its potential. I choose the lower chamber of state legislatures for empirical analysis rather than the U.S. Congress because very few states have enough congressional districts to do complete year-by-year analyses. Additionally, congressional redistricting processes are fairly uniform across the states. State legislative redistricting is controlled in more diverse ways (Hardy, Heslop, and Anderson 1981). Finally, state legislative redistricting is usually presumed more consequential in that all of the members of the (state) legislature are affected by a single, centrally controlled, redistricting process.

also become bimodal when voters in different districts respond to different cues, and hence, partisan swing becomes more variable across districts. This cause is implicit in the arguments of Erikson and Burnham, who believe that the decline in the party system is a major factor in the declining competitiveness of congressional elections. 
When a single state legislature redraws congressional district lines, only a handful of members of the entire Congress are affected by the change.

The specific evidence I present in this section is based on data from assembly elections in six states. The redistricting processes were partisan in two states, bipartisan in two, and nonpartisan in the final two. ${ }^{21}$ I use the $1970-71$ redistricting, since the 1970 s has a complete set of elections following the decennial census; a number of important court decisions during the 1960 s brought about numerous reapportionments throughout that decade, and the decade of the $1980 \mathrm{~s}$ is still unfinished.

For 1968 and 1970, and for each of the five elections following the 1970-71 redistricting, I conduct a separate analysis. The goal is to estimate $\rho$ and $\lambda$ by applying maximum likelihood to the probability distribution developed in equation 4. The basic idea of maximum likelihood analysis is to begin with this probability distribution, with which one can calculate the absolute uncertainty of any range of district-level electoral outcomes, given values for $\rho$ and $\lambda$. This measure is summarized as a "probability density," $f\left(v_{1} \mid \rho, \lambda\right)$. Thus, $\rho$ and $\lambda$ are assumed fixed, and the probability gives one a measure of the absolute uncertainty of different outcomes of $v_{1}$. However, inference is an exactly opposite problem, where the data, $v_{1}$, are known, and $\rho$ and $\lambda$ are to be estimated. Thus, maximum likelihood methods use the likelihood function $L\left(\lambda, \rho \mid v_{1}\right)$ as a relative measure of uncertainty. One then maximizes the likelihood function, which is assumed proportional to the probability distribution, with respect to $\rho$ and $\lambda$. This produces the values of $\rho$ and $\lambda$ that maximize the relative probability of getting the data we actually observe (see King 1989). A computer program to implement this estimator is available from the author. ${ }^{22}$

Note that the full stochastic model was more refined than the part to be used

${ }^{21}$ The particular states were chosen on the basis of the availability of electoral data and sufficient information about the redistricting process, both of which are in surprisingly short supply and limited availability. The data for this study were individually coded from 4,642 electoral districts in seven election years across six states from the "Blue Books" provided by their respective governments.

${ }^{22}$ In practice the log-likelihood function gives the same results as the likelihood function and is easier to work with computationally. The log-likelihood is derived by taking the product over the $D$ electoral districts and then taking logs:

$$
\begin{aligned}
\ln L(\lambda, \rho \mid v)= & D(\ln \rho+\lambda)-2 \sum_{i=1}^{D} \ln \left[e^{\lambda}+\left(\frac{v_{1 i}}{1-v_{1 i}}\right)^{\rho}\right] \\
& -(1-\rho) \sum_{i=1}^{D} \ln v_{1 i}-(1+\rho) \sum_{i=1}^{D} \ln \left(1-v_{1 i}\right)
\end{aligned}
$$

where $v_{11}$ is the proportion of votes from the Democrats in district $i$ at time 1 . Note that the presence of the second term of this expression requires that $\rho$ and $\lambda$ be estimated jointly. Numerical maximization methods are used to derive estimates and standard errors from this function. Seats are represented implicitly in this function because they are deterministic functions of votes at the district level. 
in the empirical analyses. As a result of omitting the effects of incumbency voting and partisan swing effects, these empirical analyses are only broadly indicative of general patterns and trends.

Note that the effects of partisan swing and incumbency voting analyzed in section 3 have effects on partisan bias and representation separate from any potential redistricting effects. The estimates of $\rho$ and $\lambda$ in the exploratory empirical analysis of this section thus serve only to gauge aggregate patterns. No statistical bias is introduced by omitting these effects from the empirical analysis. A very important topic for future research is to partial out explicitly the components of these broad patterns attributable to redistricting, random partisan swing, and incumbency effects. ${ }^{23}$

\section{Effects of Redistricting in Partisan States}

Indiana and Connecticut, the two states with partisan redistricting processes, were controlled by the Republican party immediately following the 1970 census. In 1971 the Republican party controlled the house, senate, and governor's office in Indiana. The redistricting plan was implemented just prior to the 1972 election in a party line vote in both houses, partially in response to the Whitcomb v. Chavis (403 U.S. 124 [1971]) Supreme Court decision allowing multimember districts. ${ }^{24}$ Connecticut's redistricting process was controlled by a three-member board composed of one Democrat, one Republican, and one supposedly neutral tie-breaker. Although the purpose of the board was to produce a bipartisan plan, with seats allocated among the parties in approximate proportion to their votes, the Republicans had effective control of the board. The Democrats even went to court, claiming an "invidious gerrymander," and sought to have the plan invalidated, but they did not succeed (see Gaffney v. Cummings 412 U.S. 735 [1973]). Both Indiana and Connecticut are strongly competitive twoparty states.

As expected, partisan bias moves closer to the Republicans from 1970 to 1972 in both Indiana and Connecticut; further, these electoral systems become somewhat more responsive (i.e., have larger values of $\rho$ ) as the Republican gerrymanderers attempted to make Democratic strongholds into marginal districts in these competitive states. These effects are conspicuous in Tables 1 and 2 , as

\footnotetext{
${ }^{23}$ One could not simply use the distribution derived in Appendix B, with incumbency and random partisan swing, with a single year of electoral data since the parameters would not be identified.

${ }^{24}$ The few multimember districts were coded as "single member districts" according to the following procedure: the Democratic candidates were ranked according to votes received from highest to lowest; Republican candidates were ranked from lowest to highest. Then each candidate pair was entered as if they were competing against each other in a single-member plurality voting election. This procedure reproduces the correct winning and losing candidates. Several other procedures, including dropping multimember districts entirely, were tried with no substantial change in substantive conclusions.
} 
TABLE 1

Partisan Redistricting in Indiana

\begin{tabular}{lrcccc}
\hline \hline Year & $\lambda$ & SE & $\rho$ & SE & Districts \\
\hline 1968 & -0.325 & 0.691 & 1.203 & 0.073 & 100 \\
1970 & 0.093 & 0.276 & 2.233 & 0.052 & 100 \\
\hline 1972 & -0.701 & 0.208 & 2.844 & 0.088 & 100 \\
1974 & 0.330 & 0.281 & 1.586 & 0.048 & 100 \\
1976 & 0.172 & 0.404 & 1.247 & 0.054 & 100 \\
1978 & 0.078 & 0.263 & 0.683 & 0.027 & 100 \\
1980 & 0.042 & 0.318 & 0.722 & 0.035 & 100 \\
\hline
\end{tabular}

TABLE 2

Partisan Redistricting in Connecticut

\begin{tabular}{cccccc}
\hline \hline Year & $\lambda$ & SE & $\rho$ & SE & Districts \\
\hline 1968 & 0.378 & 0.146 & 2.467 & 0.061 & 177 \\
1970 & 0.178 & 0.149 & 2.408 & 0.063 & 177 \\
\hline 1972 & -0.252 & 0.171 & 2.530 & 0.064 & 151 \\
1974 & 1.095 & 0.162 & 2.819 & 0.089 & 151 \\
1976 & 0.265 & 0.236 & 1.586 & 0.043 & 151 \\
1978 & 0.432 & 0.237 & 1.311 & 0.036 & 151 \\
1980 & 0.124 & 0.226 & 0.754 & 0.025 & 151 \\
\hline
\end{tabular}

both states move from slightly biased toward the Democrats to substantially biased toward the Republicans after the redistricting. ${ }^{25}$ Representation also becomes more responsive in both states, although somewhat more so in Indiana than in Connecticut. By themselves, these short-term effects are quite signifi-

${ }^{25}$ The best way to interpret the values of $\rho$ and $\lambda$ is from Figures 1 and 2. For $\lambda$ one can also calculate a percentage figure, but since partisan bias can be different depending on the value of aggregate votes $(v)$, this percentage is a function of $v$. A general way to measure bias in percentage form is to take some value of votes, say $v^{\circ}$, and to evaluate the difference between the curve, given $\rho, \lambda$, and $v^{\circ}$, and the curve, given $\rho, \lambda=0$, and $v^{\circ}$ :

$$
\begin{aligned}
\% \operatorname{BIAS}\left(v=v^{\circ}\right) & =100\left[E\left(s \mid v^{\circ}, \rho, \lambda\right)-E\left(s \mid v^{\circ}, \rho, \lambda=0\right)\right] \\
& =100\left\{\left[1+e^{-\lambda}\left(\frac{1-v^{\circ}}{v^{\circ}}\right)\right]^{-1}-\left[1+\left(\frac{1-v^{\circ}}{v^{\circ}}\right)\right]^{-1}\right\}
\end{aligned}
$$

This expression cannot be simplified in the general case. But one can easily use this to calculate the 
cant, since some empirical studies of gerrymandering have quite a difficult time demonstrating any effect at all (see Gallagher 1975; Cain 1985; Born 1985; Glazer, Grofman, and Robbins 1987). ${ }^{26}$

However, these initial effects of political gerrymandering were imperceptible in both states after only one additional election. With the 1974 Watergate swing toward the Democratic party, a 1972 bias toward the Republicans is overturned. This Democratic bias then gets smaller as the decade proceeds, but in neither state does it return to favoring the Republican party. The increase in responsiveness, presumably a result of redistricting, appears to get overtaken by incumbency effects and increases in the variance of partisan swing across the state (the latter was noted by Scarrow 1982, 820, in Connecticut). With few exceptions $\rho$ declines steadily in both Indiana and Connecticut.

These results confirm the predicted direction of partisan redistricting effects in the short term. Unfortunately, since the model does not explicitly partial out the effects of redistricting for future years, the analysis does not make clear the long-term effects of redistricting. Consistent with these results are situations where redistricting effects are nonexistent, are swamped by the dynamic effects of partisan swing and incumbency voting, or are very important but not decipherable. Since a much more complicated model is required to distinguish among these possibilities, this task is left to future research.

Furthermore, these results confirm Scarrow's (1982) analysis that the electoral system was biased in the short term by the redistricting, although he may. have slightly overestimated the 1970 Democratic advantage and underestimated the 1972 Republican bias. It also dramatically confirms his finding about the transitory effectiveness of this redistricting.

\section{Effects of Redistricting in Bipartisan States}

Much of the literature suggests that bipartisan bodies charged with redistricting responsibilities will split the advantage and tend to make $\lambda$ close to zero or, at a minimum, leave bias substantially unchanged. Furthermore, since both parties are likely to protect their respective incumbents, redistricting should leave $\rho$ noticeably smaller, making the allocation of legislative seats more insulated from small changes in voter preferences.

bias given $\lambda, \rho$, and a particular value of $\nu$. One special case, which is likely to be chosen in many instances, is $v=0.5$. In this case, this equation simplifies to:

$$
\% \operatorname{BIAS}(v=0.5)=100\left\{\left[1+e^{-\lambda}\right]^{-1}-0.5\right\}
$$

Of course, this is only part of the relationship and cannot really be substituted for the value of $\lambda$. The parameter $\lambda$ cannot be reduced to a single percentage, since the former represents a complete nonlinear relationship, whereas the latter is only a linear difference.

${ }^{26}$ The arguments in this paper all suggest comparing estimates among years within each state only. See King and Browning (1987) for an analysis of interstate differences. 
TABLE 3

Bipartisan Redistricting in Pennsylvania

\begin{tabular}{cccccc}
\hline \hline Year & $\lambda$ & SE & $\rho$ & SE & Districts \\
\hline 1968 & 0.064 & 0.148 & 1.722 & 0.040 & 203 \\
1970 & 0.377 & 0.134 & 2.287 & 0.064 & 203 \\
\hline 1972 & -0.017 & 0.182 & 1.216 & 0.028 & 203 \\
1974 & 0.353 & 0.186 & 1.251 & 0.032 & 203 \\
1976 & 0.324 & 0.242 & 0.723 & 0.028 & 203 \\
1978 & 0.066 & 0.162 & 1.120 & 0.028 & 203 \\
1980 & 0.036 & 0.158 & 0.477 & 0.017 & 203 \\
\hline
\end{tabular}

TABLE 4

Bipartisan Redistricting in Wisconsin

\begin{tabular}{lrrrrr}
\hline \hline Year & $\lambda$ & SE & $\rho$ & SE & Districts \\
\hline 1968 & -0.145 & 0.253 & 1.197 & 0.060 & 100 \\
1970 & 0.710 & 0.196 & 2.495 & 0.250 & 100 \\
\hline 1972 & 0.371 & 0.194 & 1.547 & 0.075 & 99 \\
1974 & 0.565 & 0.315 & 0.620 & 0.061 & 99 \\
1976 & 0.287 & 0.214 & 0.794 & 0.042 & 99 \\
1978 & 0.556 & 0.344 & 0.674 & 0.069 & 99 \\
1980 & 0.082 & 0.188 & 0.481 & 0.034 & 99 \\
\hline
\end{tabular}

Pennsylvania and Wisconsin are the bipartisan states in the sample. In Wisconsin a Republican senate, Democratic house, and Democratic governor failed to agree on a redistricting plan in 1971 , but an acceptable compromise was worked out during the 1972 session (Hagensick 1981). Pennsylvania was required by its state constitution to use a bipartisan commission. The commission was comprised of five members, two of which were Democrats and two Republicans. The fifth member was appointed by the state supreme court when the two partisan groups could not compromise on the remaining member. A bipartisan agreement was eventually reached among all members of the commission (see Wise 1981).

Tables 3 and 4 indicate that $\lambda$ and $\rho$ changed in predicted ways in these bipartisan states. Pennsylvania was fairly biased toward the Democrats in 1970; immediately following this bipartisan redistricting, partisan bias was essentially nonexistent. In Wisconsin the substantial Democratic bias in 1970 was nearly 
halved following the redistricting. More critically, and also as expected, $\rho$ dropped sharply from 1970 to 1972 in both states, making the allocation of legislative seats in both states considerably less responsive to changes in citizen votes.

Even given these short-term effects of legislative redistricting, these bipartisan states behaved like the other states in the years after 1972. In Pennsylvania the 1974 national Democratic swing increased bias toward the Democrats almost back to the level of the pre-redistricting 1970 election. This lasted for another election, followed by another sharp drop to negligible partisan bias. In Wisconsin the 1974 Democratic swing did not have such pronounced effects, but the general pattern of post-redistricting bias was similar. Representation in both states generally became less responsive over the decade, although it was somewhat more variable in Pennsylvania.

\section{Effects of Redistricting in Nonpartisan States}

The term "nonpartisan" is frequently a misnomer. Even avowedly nonpartisan judges and others sometimes have partisan agendas. Close historical analysis reveals that Iowa and Washington state were most nearly nonpartisan for present purposes. When the Iowa supreme court ruled the proposed legislative plan unconstitutional (on the basis of malapportionment, not bias), it drew up its own self-consciously nonpartisan plan to meet standards of minimal population deviations. The legislature essentially ratified the process by passing a law requiring "nonpartisan standards and processes" (Liittschwager 1981, 118, 1973). Washington state has a history of acrimonious redistricting battles, and the election of a Republican house and Democratic senate in 1970 added fuel to the usual fire. When the legislature could not agree, the federal court appointed a University of Washington geography professor as a special master to supervise the drawing of district lines. From all accounts, including his own, Professor Morrill's goal was to achieve an equitable and genuinely nonpartisan plan (see Morrill 1973a, 1973b).

The model developed above suggests that nonpartisan redistricting in these states will have different effects than in the partisan or bipartisan states. Presumably, a true nonpartisan would be interested in what is good for the electoral system as a whole rather than for any one political party. As such, nonpartisan redistricting should result in low levels of partisan bias and a much more responsive majoritarian electoral system.

Tables 5 and 6 indicate that redistricting seemed to have roughly these effects. Post-redistricting bias was relatively low in both states, although somewhat higher in Washington, where it actually increased slightly (but still within a single standard error bound). However, given that bias began at a low level in these states, the change in the form of democratic representation is even more significant: both states had dramatically more responsive systems immediately follow- 
TABLE 5

Nonpartisan Redistricting in Iowa

\begin{tabular}{lccccc}
\hline \hline Year & $\lambda$ & SE & $\rho$ & SE & Districts \\
\hline 1968 & -0.276 & 0.283 & 1.011 & 0.031 & 124 \\
1970 & -0.161 & 0.333 & 0.913 & 0.035 & 100 \\
\hline 1972 & -0.057 & 0.248 & 1.987 & 0.052 & 100 \\
1974 & 0.297 & 0.416 & 1.099 & 0.052 & 100 \\
1976 & 0.075 & 0.276 & 0.804 & 0.030 & 100 \\
1978 & -0.229 & 0.254 & 0.438 & 0.028 & 100 \\
1980 & -0.361 & 0.734 & 0.603 & 0.078 & 100 \\
\hline
\end{tabular}

TABLE 6

Nonpartisan Redistricting in Washington State

\begin{tabular}{lrcccc}
\hline \hline Year & $\lambda$ & SE & $\rho$ & SE & Districts \\
\hline 1968 & -0.034 & 0.232 & 0.491 & 0.024 & 99 \\
1970 & 0.053 & 0.244 & 0.579 & 0.025 & 99 \\
\hline 1972 & 0.155 & 0.271 & 1.028 & 0.035 & 98 \\
1974 & 0.293 & 0.252 & 0.544 & 0.025 & 98 \\
1976 & 0.156 & 0.244 & 0.546 & 0.025 & 98 \\
1978 & -0.033 & 0.204 & 0.347 & 0.021 & 98 \\
1980 & -0.197 & 0.286 & 0.665 & 0.031 & 98 \\
\hline
\end{tabular}

ing redistricting; $\rho$ more than doubled in Iowa and nearly doubled in Washington. Although this provides some justification for groups such as Common Cause, who want to take political redistricting out of the hands of partisan gerrymanderers, even the effect of these nonpartisan redistricting plans seem to be quickly overtaken, or covered over, by incumbency and partisan swing. Over the course of the next decade, Iowa and Washington exhibit both Democratic and Republican biases. Furthermore, neither state attains its 1972 peak in democratic responsiveness a second time. In both states $\rho$ decreases just as quickly as it increased following redistricting.

Summary of Empirical Results

In the short run redistricting appears to have effects in predicted directions. Partisan gerrymandering biases the system in favor of the party in control and, by freeing up seats held by opposition party incumbents, increases the system's 
responsiveness. Bipartisan-controlled redistricting appears to reduce bias somewhat and dramatically to reduce responsiveness. Nonpartisan redistricting processes substantially increase the systems responsiveness, but do not have as clear an effect on partisan bias.

The two nonpartisan states studied, Iowa and Washington, had quite low biases prior to redistricting; so nonpartisan redistricting plans could not have dramatically reduced partisan bias. A plausible speculation here is that the existing low pre-redistricting partisan bias was a key factor in the states' decisions to impose nonpartisan plans. If bias were more substantial earlier on, partisan or bipartisan plans might have been used.

Across all the states, clear evidence was found that redistricting had little staying power. The forces of incumbency, partisan swing, demographic movements, candidate decisions, and other factors appeared to have considerable effect on the underlying electoral system, even after accounting for the effects of redistricting. After only two elections, prima facie evidence for redistricting effects evaporate in most states. For example, even in those states where partisan bias was increased by the redistricting process, bias was not a problem by the end of the decade.

In addition, across every state and every type of redistricting process, responsiveness declined significantly over the course of the decade. This is clear evidence that the phenomenon of "vanishing marginals," recognized first in the U.S. Congress literature, also applies to these different types of state legislative assemblies. Although this finding cannot definitively establish any particular cause of this trend as the right one, it can help to rule out one: since the pattern exists across every type of redistricting process, redistricting plans that protect bipartisan incumbency could not account for all or even most of the effect. Indeed, even in those states where incumbency protection plans were not imposed, responsiveness continued to drop over the decade following the redistricting. ${ }^{27}$

\section{Concluding Remarks}

This study generalizes the aggregate theory of representation in King and Browning (1987) to allow for the possibility that legislative seats are unresponsive to citizen votes. It also uncovers some of the more fundamental district-level relationships that give rise to these concepts, defined on the level of the political system. A formal stochastic model of these district-level processes demonstrated the precise effects of incumbency and fixed and random partisan swing on rep-

${ }^{27}$ To demonstrate that this effect holds more broadly, I also conducted a test for the trend toward unresponsive representation in congressional elections by modifying the model in King and Browning (1987) and allowing $\rho$ to vary linearly with time. In $85 \%$ of the 44 states in the reanalysis, the responsiveness of congressional seats to legislative votes was found to be declining. These statelevel results on responsiveness are consistent with congressional research that finds bimodality across districts nationwide. 
resentation and bias. The paper also provides theoretical and some empirical evidence that partisan, bipartisan, and nonpartisan redistricting plans have strong predictable short-term effects on state electoral politics. Although the model developed here produces estimates of representation and bias with data from a single election year, it does not enable one completely to determine the causes of these features of electoral systems. Future research will therefore have to construct an explicit causal model so that the effects of redistricting, partisan swing, incumbency, differential turnout, and other factors on representation and bias may be disentangled.

Along the way several other contributions were also made. First, a critical assumption in this literature, dating back nearly four decades (Butler 1951), has been relaxed. Second, the study formally combines the scholarly literature on legislative redistricting with that on the decline in competitiveness, and increasing bimodality, in U.S. congressional and state legislative elections. Third, this paper has demonstrated the value of stochastic modeling for political science research-an approach to formalizing democratic theory that is much closer to the data than more common methods. Indeed, since it uses the same theoretical form as the models most researchers presume to be driving their data, it is also more realistic and easier to apply directly in empirical analyses. At the same time, stochastic modeling benefits from the same high degree of precision and rigor as other forms of formal theory. Future research is still needed to parameterize partisan swing separately; to account for uncontested seats explicitly; to allow district election results to be correlated in an explicit time series model; and to derive a model that fits a wider range of electoral data.

The issues addressed here have implications for the work of political scientists in many fields - from classical, formal, and empirical democratic theory, to public law, to empirical analyses of specific election systems in both American and comparative politics, and even to political scientists as primary expert witnesses in court testimony (Grofman 1985b). Discovering how the American system of single-member, geographically contiguous districts influences democratic representation and partisan bias must continue to play a central role in these endeavors.

Manuscript submitted 23 May 1988

Final manuscript received 21 December 1988

\section{APPENDIX A}

Fixed Incumbency and Partisan Swing Effects

Given the time 1 probability density for $V_{1}$ in equation 4 and the functional relationship between $V_{1}$ and $V_{2}$ in equation 7, the mean voter preference distribution for $V_{2}$ at time 2 may be derived in several ways. The most straightforward uses what is called the CDF technique (Bain and Engle- 
hardt 1987, 140): first note that the cumulative version of the mean voter preference distribution may be derived as follows:

$$
F_{V_{1}}\left(v_{1}\right) \equiv \operatorname{Pr}\left(V_{1} \leqslant v_{1}\right)=\int_{0}^{v_{1}} f_{v_{1}}\left(v_{1}\right) d v_{1}=\left[1+e^{\lambda}\left(\frac{1-v_{1}}{v_{1}}\right)^{\rho}\right]^{-1}
$$

Then, we derive the cumulative density for $V_{2}$ :

$$
\begin{aligned}
F_{\mathrm{V}_{2}}\left(v_{2}\right) & \equiv \operatorname{Pr}\left(V_{2} \leqslant v_{2}\right) \\
& =\operatorname{Pr}\left\{\left[1+e^{-\varepsilon}\left(\frac{1-V_{1}}{V_{1}}\right)^{\gamma}\right]^{-1} \leqslant v_{2}\right\} \\
& =\operatorname{Pr}\left\{V_{1} \leqslant\left[1+e^{\varepsilon / \gamma}\left(\frac{1-v_{2}}{v_{2}}\right)^{(1 / \gamma)}\right]^{-1}\right\} \\
& =F_{v_{1}}\left\{\left[1+e^{\varepsilon / \gamma}\left(\frac{1-v_{2}}{v_{2}}\right)^{(1 / \gamma)}\right]^{-1}\right\} \\
& =\left[1+e^{(\lambda+\varepsilon(\rho / \gamma))}\left(\frac{1-v_{2}}{v_{2}}\right)^{(\alpha / \gamma)}\right]^{-1}
\end{aligned}
$$

The derivative of this cumulative distribution gives the time 2 probability distribution of mean voter preference across districts by taking the first derivative:

$$
\begin{aligned}
f_{V_{2}}\left(v_{2}\right)= & \frac{\partial F_{V_{2}}\left(v_{2}\right)}{\partial v_{2}} \\
= & \left(\frac{\rho}{\gamma}\right) e^{(\lambda+\varepsilon(\rho / \gamma))}\left[e^{(\lambda+\varepsilon(\rho / \gamma))}+\left(\frac{v_{2}}{1-v_{2}}\right)^{(\alpha / \gamma)}\right]^{-2} \\
& \times v_{2}^{-(1-\rho)(\gamma)}\left(1-v_{2}\right)^{(1+\rho / \gamma)}
\end{aligned}
$$

and the corresponding time 2 seats-votes curve (calculated by the assumption in equation 5) is

$$
\begin{aligned}
E\left(S_{2}\right) & =\int_{0}^{\mu_{2}} f_{V_{2}}\left(1-\mu_{2}\right) d \mu_{2} \\
& =1-F_{V_{2}}\left(1-\mu_{2}\right) \\
& =\left[1+e^{-(\lambda+\varepsilon(\rho) \gamma))}\left(\frac{1-\mu_{2}}{\mu_{2}}\right)^{(\rho / \gamma)}\right]^{-1}
\end{aligned}
$$

\section{APPENDIX B \\ Random Partisan Swing}

Begin with the assumption that partisan swing, $\varepsilon$, is uniformly distributed:

$$
\varepsilon \sim U(\varepsilon)= \begin{cases}(2 \theta)^{-1} & \text { for } \tau-\theta \leqslant \varepsilon \leqslant \tau+\theta, \theta>0 \\ 0 & \text { otherwise }\end{cases}
$$

I incorporate this new assumption into the model in several steps. First, note that equation 9 is really a conditional distribution of $V_{2}$ on $\varepsilon$ (as well as the other parameters). Then, write the joint distribution of $V_{2}$ and $\varepsilon$ as the product of $U(\varepsilon)$ and $f_{V_{2}}\left(v_{2}\right) \equiv f_{V_{2}}\left(v_{2} \mid \varepsilon\right)$ : 


$$
\begin{aligned}
f_{V_{2}}\left(\nu_{2}, \varepsilon\right)= & U(\varepsilon) f_{V_{2}}\left(\nu_{2} \mid \varepsilon\right) \\
= & (2 \theta)^{-1}\left(\frac{\rho}{\gamma}\right) v_{2}^{-(1-\rho(\gamma)}\left(1-v_{2}\right)^{(1+\rho / \gamma)} \\
& \times e^{(\lambda+\varepsilon(\rho) \gamma)]}\left[e^{(\lambda+\varepsilon(\rho / \gamma))}+\left(\frac{v_{2}}{1-v_{2}}\right)^{\rho / \gamma}\right]^{-2}
\end{aligned}
$$

Now integrate out $\varepsilon$ to leave the new time 2 mean voter preference distribution:

$$
\begin{aligned}
& f V_{2}^{\prime}\left(\nu_{2}\right)=\int_{-x}^{x} f_{V_{2}^{\prime}}\left(v_{2}, \varepsilon\right) d \varepsilon \\
& =(2 \theta)^{-1} v_{2}^{-(1-\rho \gamma \gamma)}\left(1-v_{2}\right)^{-(1+\rho(\gamma)} \\
& \times \int_{\tau-\theta}^{\tau+\theta}\left(\frac{\rho}{\gamma}\right) e^{(\lambda+\theta)(\rho / \gamma))}\left[e^{(\lambda+\varepsilon(\rho) \gamma /))}+\left(\frac{v_{2}}{1-v_{2}}\right)^{\rho / \gamma}\right]^{-2} d \varepsilon \\
& =(2 \theta)^{-1} v_{2}^{-(1-\rho / \gamma)}\left(1-v_{2}\right)^{-(1+\rho(\gamma)} \\
& \times\left\{\left[e^{[\lambda+\{\tau-\theta) \rho i p]}+\left(\frac{v_{2}}{1-v_{2}}\right)^{\alpha / \gamma}\right]^{-1}\right. \\
& \left.-\left[e^{[\lambda+(\tau+\theta) \rho(\gamma]}+\left(\frac{v_{2}}{1-v_{2}}\right)^{\rho / \gamma}\right]^{-1}\right\}
\end{aligned}
$$

By the application of assumption 5 , the corresponding seats-votes curve is then:

$$
\begin{aligned}
E\left(S_{2}^{\prime}\right)= & \int_{0}^{v_{2}} f V_{2}^{\prime}\left(1-v_{2}\right) d v_{2} \\
= & \left(\frac{\rho}{\gamma} 2 \theta\right)^{-1}\left\{\ln \left[e^{[\lambda+(\tau+\theta) \rho / \gamma]}+\left(\frac{1-v_{2}}{v_{2}}\right)^{\rho / \gamma}\right]\right. \\
& \left.-\ln \left[e^{[\lambda+(\tau-\theta) \rho / \gamma]}+\left(\frac{1-v_{2}}{v_{2}}\right)^{\rho / \gamma}\right]\right\}
\end{aligned}
$$

Note that $\varepsilon$ does not appear directly in either the modified mean voter preference distribution or this corresponding seats-votes curve. However, the mean $(\tau)$ and the dispersion $(\theta)$ of the distribution of $\varepsilon$ are included. By this procedure, then, the model has one additional parameter.

\section{REFERENCES}

Achen, Christopher. 1986. The Statistical Analysis of Quasi-Experiments. Berkeley: University of California Press.

Ansolabehere, Stephen, David Brady, and Morris Fiorina. 1988. "The Marginals Never Vanished?" Mimeo., Stanford University.

Backstrom, Charles, Leonard Robins, and Scott Eller. 1978. "Issues in Gerrymandering: An Exploratory Measure of Partisan Gerrymandering Applied to Minnesota." Minnesota Law Review $62: 1127-59$.

Bain, Lee J., and Max Engelhardt. 1987. Introduction to Probability and Mathematical Statistics: Boston: Duxbury.

Bandemer v. Davis. 1984. 603 F. Supp. 1479, S.D. Ind. 
Born, Richard. 1985. "Partisan Intentions and Election Day Realities in the Congressional Redistricting Process." American Political Science Review 79:305-19.

Browning, Robert X., and Gary King. 1987. "Seats, Votes, and Gerrymandering: Estimating Representation and Bias in State Legislative Redistricting." Law and Policy 9:305-22.

Burnham, Walter Dean. 1974. "Communications." American Political Science Review 68:210.

Butler, David E. 1951. Appendix. In H. G. Nicholas, The British General Election of 1950. London: Macmillan.

Cain, Bruce. 1984. The Reapportionment Puzzle. Berkeley: University of California Press.

. 1985. "Assessing the Partisan Effects of Redistricting." American Political Science Review $79: 320-33$

Davis v. Bandemer. 1986. 106 S.Ct. 2797.

Dixon, Robert G., Jr. 1968. Democratic Representation: Reapportionment in Law and Politics. New York: Oxford University Press.

Erikson, Robert S. 1972. "Malapportionment, Gerrymandering, and Party Fortunes in Congressional Elections." American Political Science Review 66:1234-45.

Ferejohn, John A. 1977. "On the Decline of Competition in Congressional Elections." American Political Science Review 71:166-76.

Fiorina, Morris. 1977. Congress: Keystone of the Washington Establishment. New Haven: Yale University Press.

Gaffney v. Cummings. 1973. 412 U.S. 735.

Gallagher, Michael. 1975. "Disproportionality in a Proportional Representation System: The Irish Experience." Political Studies 23:501-13.

Glazer, Amihai, Bernard Grofman, and Marc Robbins. 1987. "Partisan and Incumbency Effects of 1970s Congressional Redistricting." American Journal of Political Science 31:680-707.

Grofman, Bernard. 1983. "Measures of Bias and Proportionality in Seats-Votes Relationships." Political Methodology 9:295-327.

_. 1985a. "Criteria for Districting: A Social Science Perspective." UCLA Law Review 33:77-184.

_. 1985b. "Political Gerrymandering: Badham v. Eu, Political Science Goes to Court." Political Science 538-81.

Grofman, Bernard, and Arend Lijphart. 1986. Electoral Laws and Their Political Consequences. New York: Agathon.

Grofman, Bernard, Arend Lijphart, R. B. McKay, and Howard A. Scarrow, eds, 1982. Representation and Redistricting 1ssues. Lexington, MA: D. C. Heath.

Gudgin, G., and P. J. Taylor. 1979. Seats, Votes, and the Spatial Organization of Elections. London: Pion.

Hagensick, A. Clarke. 1981. "Wisconsin." In Reapportionment Politics: The History of Redistricting in the 50 States, ed. Leroy Hardy, Alan Heslop, and Stuart Anderson. Beverly Hills: Sage.

Hardy, Leroy, Alan Heslop, and Stuart Anderson, eds. 1981. Reapportionment Politics: The History of Redistricting in the 50 States. Beverly Hills: Sage.

Jacobson, Gary C. 1987. "The Marginals Never Vanished: Incumbency and Competition in Elections to the U.S. House of Representatives." American Journal of Political Science 31:126-41.

Johnson, Norman L., and Samuel Kotz. 1972. Continuous Distributions. Vols. 1 and 2. New York: Wiley.

King, Gary. 1989. Unifying Political Methodology: The Likelihood Theory of Statistical Inference. New York: Cambridge University Press.

King, Gary, and Robert X. Browning. 1987. "Democratic Representation and Partisan Bias in Congressional Elections." American Political Science Review 81: 1251-76.

Liittschwager, John M. 1973. "The Iowa Redistricting System." Annals of the New York Academy of Sciences 219:221-35. 
1981. "Iowa." In Reapportionment Politics: The History of Redistricting in the 50 States, ed. Leroy Hardy, Alan Heslop, and Stuart Anderson. Beverly Hills: Sage.

Lijphart, Arend. 1984. Democracies. New Haven: Yale University Press.

Mayhew, David R. 1971. "Congressional Representation: Theory and Practice in Drawing the Districts." In Reapportionment in the 1970s, ed. Nelson W. Polsby. Berkeley: University of California Press.

1974. Congress: The Electoral Connection. New Haven: Yale University Press.

Morrill, Richard. 1973a. "On the Criteria for Redistricting." Washington Law Review 48:847-56. . 1973b. "Ideal and Reality in Reapportionment." Annals of the Association of American Geographers 63:463-77.

Niemi, Richard G. 1985. "The Relationship between Votes and Seats: The Ultimate Question in Political Gerrymandering." UCLA Law Review 33:185-212.

Niemi, Richard G., and John Deegan, Jr. 1978. "A Theory of Political Districting." American Political Science Review 72:1304-23.

Niemi, Richard G., and Patrick Fett. 1986. "The Swing Ratio: An Explanation and an Assessment." Legislative Studies Quarterly 11:75-90.

Owen, Guillermo, and Bernard Grofman. 1988. "Optimal Partisan Gerrymandering." Political Geography Quarterly 7:5-22.

Polsby, Nelson W., ed. 1971. Reapportionment in the 1970s. Berkeley: University of California Press.

Quandt, Richard E. 1974. "A Stochastic Model of Elections in Two-Party Systems." Journal of the American Statistical Association 69:315-24.

Rae, Douglas W. 1971. The Political Consequences of Electoral Laws. Rev. ed. New Haven: Yale University Press.

Scarrow, Howard A. 1982. "Partisan Gerrymandering-Invidious or Benevolent? Gaffney v. Cummings and Its Aftermath." Journal of Politics 44:810-21.

Schrodt, Philip A. 1981. "A Statistical Study of the Cube Law in Five Electoral Systems." Political Methodology 7:31-53.

Tufte, Edward. 1973. "The Relationship between Seats and Votes in Two-Party Systems." American Political Science Review 67:540-54.

Whitcomb v. Chavis. 1971. 403 U.S. 124.

Wise, Sidney. 1981. "Pennsylvania." In Reapportionment Politics: The History of Redistricting in the 50 States, ed. Leroy Hardy, Alan Heslop, and Stuart Anderson. Beverly Hills: Sage. 